\title{
Equity returns following changes in default risk: New insights into the informational content of credit ratings. ${ }^{\ominus}$
}

\author{
Maria Vassalou* \\ and \\ Yuhang Xing ${ }^{* *}$
}

First Draft: October 30, 2002

This Draft: July 18, 2003

\footnotetext{
$\checkmark$ The latest version of the paper can be downloaded from http://www.gsb.columbia.edu/faculty/mvassalou/

* Corresponding Author: Graduate School of Business, Columbia University, 416 Uris Hall, 3022

Broadway, New York, NY 10027, tel: 212-854 4104, e-mail: maria.vassalou@,columbia.edu

** Graduate School of Business, Columbia University, 313 Uris Hall, 3022 Broadway, New York, NY 10027, e-mail: yx35@columbia.edu
} 


\title{
Equity returns following changes in default risk: New insights
}

\section{into the informational content of credit rating changes.}

\begin{abstract}
Previous studies report the existence of persistent abnormal negative equity returns following downgrades, and the absence of an equity reaction following upgrades. The above result is viewed as a puzzling anomaly, and there are attempts to explain it using behavioral theories. In this paper, we show that the above result is specific to the method used in previous studies to compute abnormal returns. In particular, we show that when returns are adjusted for the variation in default risk around downgrades, the abnormal negative returns in short horizons disappear. We use Merton's (1974) model to compute the default risk of firms each month. We then show that, consistent with rational behavior, firms whose default risk goes up earn higher subsequent returns than firms whose default risk goes down. We also note that many of the firms that experience a downgrade are bound to be downgraded again in the three-year period following the initial downgrade. When this fact is taken into account, any abnormal negative returns in the 2- to 3-year horizon also disappear. Our analysis has implications for the information content of credit ratings, as well as for the value that rating agencies provide to the investment community.
\end{abstract}

Keywords: default risk, Merton's (1974) model, abnormal equity returns, credit rating downgrades/upgrades, size, book-to-market.

JEL classifications: G33, G14, G29 


\section{Introduction}

Several studies suggest that abnormal equity returns following bond downgrades are negative, whereas there is no significant abnormal equity return reaction subsequent to upgrades - see for instance, Holthausen and Leftwich (1985), Hand, Holthausen and Leftwich (1992), and Dichev and Piotroski (2001).

These results are considered puzzling for two reasons. First, there is no a priori reason why equity returns should react to upgrades and downgrades in an asymmetric fashion. Second, given that a downgrade implies an increase in the default risk of the firm, one would expect that rational investors will require a higher - not lower - expected return to hold the stock of that firm. The above results are even more puzzling when one considers that the negative abnormal equity returns persist for about three years following a downgrade (see, Dichev and Piotroski (2001)). Abnormal returns are calculated by subtracting the returns of benchmark portfolios with similar size and book-to-market (BM) characteristics. The explanation that Dichev and Piotroski provide for those results is that they are due to investors' underreaction to the information content of downgrades.

In this paper, we shed new light on the relation between changes in default risk and subsequent (abnormal) equity returns. Using an alternative-to-bond-ratings measure of default risk, we show that stocks with large increases in their default risk earn significantly higher subsequent returns than stocks with large decreases in their default risk. This result is consistent with economic intuition which dictates that investors will require a higher return to hold stocks with higher (default) risk. 
It is, however, obviously contrary to what was found in the previous studies and discussed above. In our study, we reconcile the two sets of results and provide new insights into the informational content of bond upgrades and downgrades.

Our measure of default risk follows from the contingent claims approach of Merton (1974). Merton views equity as a call option on the firm's assets, with the exercise price of the option being the book value of the firm's debt. Using the BlackScholes (1973) formula, one can obtain a default likelihood indicator (DLI) of the firm's prospects to default. The DLI of each firm can be updated frequently, and in our application it is updated every month. It therefore provides a better estimate of a firm's current chances to default than a bond rating, which is typically not updated more often than once a year. ${ }^{1}$

We associate changes in DLIs to changes in credit ratings. In the case of downgrades, the results show clearly that the average DLI for all downgrades starts increasing about two to three years prior to the downgrade, and reaches its peak at time zero, the date of the downgrade announcement. This result was largely to be expected, since some substantial change in the default risk of a firm has to occur for a downgrade to take place. What is surprising, however, is the fact that the average DLI starts decreasing following the downgrade, at about the same rate at which it increased in the first place. Furthermore, it returns to almost the same level it had three years prior to the downgrade. In other words, the graph of average DLI as a function of time around the downgrade

\footnotetext{
${ }^{1}$ There is evidence that in fact only a small percentage of ratings are updated every year. Zonana and Hertzberg (1981) for instance reports that about 2,000 out of 18,000 outstanding ratings are reviewed per year, whereas Weinstein (1977) suggests that more than half of the reviews are associated with new debt issues. Therefore, most bond ratings reflect "stale" information about a firm's prospects to default.
} 
(plus-minus 36 months) has an inverted V-shape, with the peak placed on the announcement date of the downgrade.

The above finding implies that equity returns following a downgrade should be lower, given that the firm's default risk is lower. It also implies that it is important to adjust for the variation in DLI when calculating abnormal equity returns following a downgrade. Indeed, if equity returns are adjusted not only for size and BM, but also for DLI, the short-horizon negative abnormal equity returns found in Dichev and Piotroski (2001) disappear. Some negative abnormal returns are still found in the two- to three-year horizon. However, about $42 \%$ of stocks with a downgrade experience subsequent downgrades in the three-year period following the initial one. When this fact is also taken into account, the economically significant negative abnormal returns disappear completely.

The inverted V-pattern in DLI around downgrades is most pronounced for firms with C-grade debt, with the rate of change in default risk being particularly high during the year surrounding the announcement of the downgrade. The change in default risk surrounding the downgrade is less pronounced in the case of firms with grade-B debt, and non-existent in the case of firms with grade-A debt. These results are consistent with those in Dichev and Piotroski (2001), in the sense that they explain why the negative returns following a downgrade are most pronounced for small non-investment grade firms. The reason is that most firms with low-grade debt are small, and the reduction in default risk following a downgrade is steeper in their case, than it is for larger, investment grade firms. Therefore, in those cases, it is even more important to take into account the DLI of the firms in calculating their abnormal returns. 
The picture that emerges in the case of upgrades is quite different from that described above. In the case of a symmetric equity returns response to upgrades and downgrades, we would expect that the inverted V-shape pattern of the average DLI for the downgrades will be replaced by a V-shaped plot in the case of upgrades. This is not what we observe, however. The line of average DLI for all firms is almost flat, with a slight dip on the announcement date of the upgrade. This dip is so small, that it cannot be possibly associated with a significant increase in subsequent equity returns. We observe a rapid decrease in default risk for grade $\mathrm{C}$ firms prior to an upgrade, but the subsequent-tothe-announcement-date increase is again relatively small to give rise to large positive returns. In other words, the asymmetry observed in previous studies in the reaction of equity returns to downgrades and upgrades can be explained by the asymmetric change in average DLI to credit rating changes, depending on the nature of the event (i.e., upgrade or downgrade.) DLI varies a lot around downgrades, but not around upgrades. Therefore, adjusting for DLI in calculating abnormal equity returns following downgrades is of essence, whereas it is immaterial in the case of upgrades, since DLI exhibits little, if any, variation in the latter case.

Given the relation between credit rating changes and DLI uncovered in this study, the natural questions that come to mind are the following. What is the information content of credit ratings, and what service do changes in credit ratings really provide to the investors? These questions are particularly important since it follows from our analysis that default risk varies too much over time for credit ratings to provide any useful information about the future default risk of a firm. Furthermore, it seems from our results that a grouping of stocks according to their credit rating (A, B, or C) provides 
almost identical information about default risk as a classification of firms into size or book-to-market (BM) tertiles.

One can argue that although credit ratings contain little genuine information, downgrades have a disciplinary effect on the firms. To understand this argument, notice that although DLIs can be computed on the basis of publicly availably information, they are not publicly available information themselves. They are costly to compute or purchase. ${ }^{2}$ Furthermore, it is likely that only sophisticated investors have access to them. In contrast, downgrades are publicly available information and constitute "events". Since DLIs are not observable, firms can pursue their risky strategies and increase their risk of default, without the market as a whole observing that. Once a downgrade occurs, the market becomes aware of the fact that a substantial increase in default risk took place in the recent past to warrant such an action. A downgrade reduces the firm's ability to borrow and roll-over its short-term debt. Furthermore, downgrades are often accompanied by policy recommendations from the part of the credit rating agency, advising the firm of the actions it should take to reduce its default risk. The increased borrowing constraints and the publicity surrounding the downgrade puts pressure on the firm's management to streamline its business and reduce its debt. The result is a reduction in the firm's DLI following a downgrade.

If the true service offered by the credit rating changes is a disciplinary effect on the firm, then we would not expect to find a symmetric response in the change of DLI and in the equity returns following an upgrade. An upgrade implies that the firm is doing well and deserves to be "rewarded" by an upgrade of its credit rating. This upgrade eases

\footnotetext{
${ }^{2}$ For instance, KMV is a commercial provider of default probabilities along the lines of the DLIs used in this study.
} 
up its cost of borrowing and provides more flexibility to the management of the firm. Whereas some firms may be tempted to increase their default risk following an upgrade, most firms don't, most likely because they do not have to.

The remainder of the paper is structured as follows: Section 1 discusses the approach used to calculate the default likelihood indicators. Section 2 describes the data and provides summary statistics. In Section 3 we examine the relation between changes in default risk and subsequent equity returns in different horizons and for firms with different characteristics. Section 4 relates changes in our measure of default risk to changes in credit ratings and provides an interpretation for the informational content of upgrades and downgrades. We conclude in Section 5 with a summary of our results.

\section{Computing Default Likelihood Indicators (DLIs)}

As mentioned earlier, we follow Merton's (1974) insight in calculating the default likelihood indicator (DLI) of a firm, and therefore view the equity of the firm as a call option on the firm's assets. This implies that in the Black and Scholes (B-S)(1973) option pricing formula, the underlying asset is the value of the firm's assets, $\mathrm{V}_{\mathrm{A}}$, the strike price is the book value of the firm's debt, $\mathrm{X}$, and the value of the call is the value of the firm's equity, $\mathrm{V}_{\mathrm{E}}$. In other words,

$$
V_{E}=V_{A} N\left(d_{1}\right)-X e^{-r T} N\left(d_{2}\right)
$$

where $d_{1}=\frac{\ln \left(V_{A} / X\right)+\left(r+\frac{1}{2} \sigma_{A}^{2}\right) T}{\sigma_{A} \sqrt{T}}, d_{2}=d_{1}-\sigma_{A} \sqrt{T}, r$ is the risk free rate, and $N$ is the cumulative density function of the standard normal distribution. 
In applying the B-S formula for the purposes of calculating a firm's DLI, we follow an identical methodology to that in Vassalou and Xing (2003), and similar to the one used by KMV. ${ }^{3}$ Vassalou and Xing (2003) show that default risk, as proxied by DLI, is priced in the cross-section of equity returns, and therefore, it constitutes systematic risk. They also provide evidence on the ability of DLI to predict future defaults, and its performance relative to other measures. For instance, they show that DLI contains much more information about future defaults than measures based solely on the market value of equity or the volatility of equity.

The approach used to compute DLI is as follows. We calculate each month the likelihood that a firm will default over the next 12 months. To do that, we need to obtain estimates of the volatility of assets, $\sigma_{\mathrm{A}}$, and the value of assets. At first, it seems that this task is impossible, since we have one equation and two unknowns. However, the problem can be solved by adopting an iterative process, which amounts to using a time-series of equations to estimate two unknowns.

In particular, we first estimate the volatility of equity, $\sigma_{\mathrm{E}}$, using daily data from the past 12 months. This estimate is used as an initial value for the estimation of $\sigma_{\mathrm{A}}$, and for nothing else. We then employ the B-S formula for each trading day of the past 12 months, and compute $V_{A}$ using as $V_{E}$ the market value of equity for that day. In that manner, we obtain a time-series of $\mathrm{V}_{\mathrm{A}}$ 's from a time-series of B-S equations. The next step is to calculate the standard deviation of those $\mathrm{V}_{\mathrm{A}}$ 's, which will be used as the value of $\sigma_{\mathrm{A}}$ for the following iteration. The process is repeated until the standard deviations of

\footnotetext{
${ }^{3}$ For details about KMV's methodology, see Crosbie (1999). For a comparison of KMV's methodology with that in Vassalou and Xing (2003), see Vassalou and Xing (2003).
} 
$\mathrm{V}_{\mathrm{A}}$ 's from two consecutive iterations converge. Our tolerance level for convergence is 10E-4.

The probability of default implied by the B-S model is the following:

$$
\begin{aligned}
& P_{d e f, t}=\operatorname{Pr} o b\left(\ln \left(V_{A, t}\right)-\ln \left(X_{t}\right)+\left(\mu-\frac{\sigma_{A}{ }^{2}}{2}\right) T+\sigma_{A} \sqrt{T} \varepsilon_{t+T} \leq 0\right) \\
& P_{d e f, t}=\operatorname{Pr} o b\left(-\frac{\ln \left(\frac{V_{A, t}}{X_{t}}\right)+\left(\mu-\frac{\sigma_{A}{ }^{2}}{2}\right) T}{\sigma_{A} \sqrt{T}} \geq \varepsilon_{t+T}\right)
\end{aligned}
$$

The concept of distance-to-default (DD) is defined as follows:

$$
D D_{t}=\frac{\ln \left(V_{A, t} / X_{t}\right)+\left(\mu-\frac{1}{2} \sigma_{A}{ }^{2}\right) T}{\sigma_{A} \sqrt{T}}
$$

The probability of default is given then by:

$$
P_{d e f}=N(-D D)=N\left(-\frac{\ln \left(V_{A, t} / X_{t}\right)+\left(\mu-\frac{1}{2} \sigma_{A}{ }^{2}\right) T}{\sigma_{A} \sqrt{T}}\right)
$$

As in Vassalou and Xing (2003), the number of defaults in our database is relatively small, which makes it difficult to compute the empirical distribution of defaults. For that reason we follow Vassalou and Xing (2003), and call our measure Default Likelihood Indicator (DLI), rather than default probability. The reason is that the measure does not correspond to a default probability in large samples, because it is calculated based on the theoretical (normal) distribution of defaults, rather than the empirical distribution. It is, however, a positive non-linear function of the underlying 
true default probability. This difference is not material for the purposes of our study, as it does not affect the ranking of the firms.

Note that equation (4) involves the mean of the change in the value of assets, $\mu$. In our application, $\mu$ is computed as the mean of the daily changes in the log value of assets over the 12 months for which DLI is computed. It is well-known that means are notoriously hard to estimate, and the current application is no exception. However, it is important to stress that the properties of DLI and its ability to capture default risk does not depend on the estimate of $\mu$. Indeed, if we replace $\mu$ with the risk-free rate, $r$, the results of this study remain unchanged. Using $r$ instead of $\mu$ in equation (4) corresponds to computing default probabilities under the risk-adjusted probability measure Q.

As a measure of debt, we use the firm's short-term debt, plus half of its long-term debt. It is important to take into account the firm's long-term debt, since it affects its ability to roll-over its short-term debt. How much of the long-term debt should be included in the strike price of the call option is an arbitrary choice. KMV uses $50 \%$, and argues that it is a sensible choice that captures adequately the financing constraints of firms. Vassalou and Xing (2003) do the same and we follow this choice.

\section{Data and summary statistics}

The main sources of our data are the CRSP, Compustat, and Moody's bond ratings databases. 
We use CRSP to obtain daily values of the firms' market value of equity. The debt information is obtained from Compustat. In particular, we use the series "Debt in One Year" and "Long-Term Debt". We also obtain from Compustat the book value of firms. These data are annual, and to avoid problems related to reporting delays, we do not use a firm's book value, until four months have elapsed from the end of its fiscal year. Firms with negative book values are excluded from our sample.

Data on bond ratings are obtained from Moody's database, and include the dates of upgrades and downgrades. Table 1 provides a summary of the number of firms per year in our database, as well as the number of upgrades and downgrades. Our database starts in 1971, which corresponds to the year for which Compustat debt data for a large number of firms become available. ${ }^{4}$

Table 1 also provides information about the mean book-to-market (BM), market capitalization (size) and DLI for all firms classified by bond rating. We use three broad categories: A, B, and C. Specifically, we group all stocks whose Moody's bond ratings start with A in the A category, all those that start with B in the B category, and all those that start with $\mathrm{C}$ in the $\mathrm{C}$ category. We also report all the upgrades and downgrades observed during our sample by grading category, size tertile, and BM tertile.

Table 2 provides summary statistics for the DLIs of all firms and the changes in DLI, denoted by CDLI. We report statistics for the average DLI and CDLI of all firms in our sample, as well as the return, CDLI and DLI of size quintiles and BM quintiles. It is apparent that big increases in DLI occur in the small size and high BM quintiles, whereas the biggest decreases are observed for the big and low BM quintiles. In other words, not only is the risk of default (DLI) higher for small firms and high BM firms,

\footnotetext{
${ }^{4}$ Note that Moody's database starts in 1970.
} 
but the biggest average increases in default risk are also observed for the same portfolios.

As a proxy for the risk-free rate for the computation of DLI, we use the one-year Treasury Bill rate obtained from the Federal Reserve Board Statistics. However, when we compute abnormal returns (alphas), we use the one-month risk-free rate obtained from Kenneth French's website. Data for the Fama-French (1993) factors SMB, HML, and the excess return on the equity market portfolio EMKT are also obtained from Kenneth French. ${ }^{5}$

\section{Changes in default risk and subsequent equity returns}

In this section, we re-examine the stylized fact that abnormal equity returns following increases in default risk are negative. However, instead of using bond downgrades as a measure of increases in default risk, we use increases in DLI. DLIs represent a better estimate of default risk than bond ratings because they are computed based on market prices, and therefore forward-looking information. In addition, they are updated every month, whereas bond ratings are usually not updated more often than once a year. ${ }^{6}$ In Section 4, we will examine in detail the relation between DLIs and bond ratings, and provide new insights into the relation between DLIs and bond upgrades/downgrades.

\subsection{The properties of portfolios sorted on changes in default risk}

\footnotetext{
${ }^{5}$ We thank Ken French for making the data available on his webpage. Details about the data, as well as the actual data series can be obtained from http://mba.tuck.dartmouth.edu/pages/faculty/ken.french/

${ }^{6}$ For a detailed discussion on the properties and performance of DLIs, see Vassalou and Xing (2003).
} 
In Table 3 we provide results on the properties of portfolios sorted on changes in default risk (CDLI), as measured by changes in the default likelihood indicators of firms. Panel A reports the average returns for different holding periods of decile portfolios. The returns reported here are raw returns, not abnormal returns. We will discuss abnormal returns in Section 3.2. The returns we report are equally-weighted, but the results remain qualitatively the same when value-weighted returns are calculated instead.

Returns for short holding-period horizons of the high CDLI portfolio are higher than those of low CDLI portfolio. At the one-month holding period horizon, the difference in returns is $2.17 \%$ per month or $26 \%$ per annum (p.a.), and evidently statistically significant. This impressive return is consistent in magnitude with the returns reported in Vassalou and Xing (2003) for portfolios sorted on DLI. Positive returns following increases in default risk are consistent with the behavior of rational investors who require higher returns to hold equities that have become riskier.

The return difference decreases as the holding period increases, and is no longer statistically significant after the six-month horizon. Even at six months, the difference in returns between high and low CDLI portfolios is only 15 basis points (b.p) per month.

Panel B provides an explanation for this result. The turnover of these portfolios is very high. For the one-month holding period horizon, the turnover of the portfolio is around $70 \%$. This means that about $70 \%$ of the portfolio composition changes from one month to the other. To gain intuition into the high turnover of these portfolios, recall that in Merton's (1974) model, equity is viewed as a call option on the firm's assets. It 
is apparent from equation (4) that every time the market value of assets and the volatility of assets change, the DLI will change too. Since the market value of equity and debt change for most firms on a daily basis, the default risk of those firms changes with the same frequency. Given the above, it is not surprising that the return difference between high and low CDLI portfolios decreases as the holding period increases. If DLIs change so rapidly, failure to rebalance the portfolio frequently results into a portfolio that has very different default risk properties at the end of the holding period than it had at formation. This in turn implies that there is little scope in examining longrun returns of portfolios sorted on CDLI, since DLI changes so quickly. For that reason, and for the remaining of this section, we will concentrate on the one-month holding period horizon when we discuss the relation between equity returns following changes in DLI. ${ }^{7}$

Notice that the turnover of the extreme portfolios (1 and 10) is slightly lower than that of the remaining portfolios. The reason is that changes in DLI in the other portfolios are generally very small, resulting in assets shifting between adjacent portfolios very frequently. In contrast, CDLIs for portfolios 1 and 10 are typically large in absolute value.

It is also worthwhile to note that both portfolios 1 and 10 contain stocks that are in most cases small caps and high BM. This means that most dramatic (positive or negative) changes in DLI occur in small, high BM stocks, whereas the DLI is more

\footnotetext{
${ }^{7}$ As mentioned earlier, previous studies use credit ratings to examine the effect of changes in default risk on equity returns. There are only a few credit rating categories, and therefore, stocks that belong to any given one may exhibit at best a whole range of DLIs. Since credit ratings are updated rather infrequently, this range of DLIs can be potentially very large. One point to be taken away from the results presented above is that for credit ratings to be useful as measures of default risk, they need to be updated more often.
} 
stable for the remaining stocks in the market. Small, high BM stocks are also those that have the lowest credit ratings, as shown in Section 4.1.1.

Panel $\mathrm{C}$ of Table 3 shows the average returns for portfolios constructed over different formation periods. The holding period is always one month. Again, it is apparent that the returns for the zero-investment (10-1) portfolio are higher when the formation period is short. Once more, this result is due to the rapid change in DLI, which dictates that the highest return differences are obtained for portfolios that are rebalanced every month, and are constructed on the basis of changes in DLI over the past month.

The conclusion that emerges from Table 3 is that increases in default risk measured by increases in the DLIs of stocks are followed by increased equity returns. As mentioned, this is consistent with the behavior of rational investors that demand higher returns for stocks that became riskier.

\subsection{Abnormal equity returns following changes in default risk}

Previous papers in the literature focus on the abnormal equity returns following credit rating changes, and show that abnormal returns are negative following downgrades. In this section, we calculate risk-adjusted (abnormal) returns for the one-month holding/formation period portfolios discussed in Section 3.1.

Since we have time-series of returns for those portfolios, we can examine abnormal returns by computing the alphas of those portfolios implied by standard asset

pricing models. In particular, we compute alphas based on the Capital Asset Pricing Model (CAPM), the Fama-French (FF) (1993) model, and Carhart's (1997) model that 
includes a momentum factor in addition to the FF factors. The momentum factor is denoted by WML (winners minus losers). It is a portfolio that is long on the best performing stocks over the past year and short on the worst performing stocks over the same time period.

The alphas are reported in Table 4. The results show that the abnormal returns of portfolio 1, which contains the stocks with the biggest decreases in default risk, are negative, independently of which model is used to calculate the alphas. In other words, the one-month abnormal returns following big decreases in default risk are negative. In contrast, the abnormal returns for portfolio 10, which includes the stocks with the biggest increases in default risk, are always positive. Put differently, when default risk increases substantially, as shown in Table 3, stocks earn a significantly positive abnormal return.

These results are in sharp contrast to those found in the literature. Increases in default risk are followed by positive abnormal returns, whereas decreases in default risk are followed by abnormal negative returns.

An important point needs to be stressed at this point. The returns reported in Table 4 are abnormal to the extent that the asset pricing models used to compute them are correct. However, there is little evidence that any of the factors considered captures adequately default risk. Whereas Fama and French (1996) argue that their proposed factors proxy for financial distress, Vassalou and Xing (2002) find little evidence that this is indeed the case. In other words, the "abnormal" returns reported in Table 4 may be simply rewards for default risk not reflected in the factors of the models considered. ${ }^{8}$

\footnotetext{
${ }^{8}$ Constructing a returns-based factor that perfectly captures default risk is not a simple task. Such an exercise is beyond the scope of this study which focuses mainly on the default information in credit ratings.
} 
Nevertheless, the alphas reported in Table 4 are appropriate for comparing our results to those of the literature. Previous studies calculate abnormal returns by either taking into account the return on the market portfolio (Holthausen and Leftwich (1986)), or adjusting individual equity returns by the returns of portfolios with similar size and BM characteristics (Dichev and Piotroski (2001)). Both sets of factors are reflected in the models we examine. In all cases, our results contradict those found in the previous studies.

\subsection{Changes in default risk, level of default risk and firm characteristics.}

How does a stock's level of default risk affect its chances to experience large positive or negative changes in default risk? This question is addressed in Table 5.

We sort stocks according to their DLI into quintiles. We then sort each quintile into five portfolios according to CDLI. Once again, we observe that the highest returns (3.65\% per month) are obtained by stocks that are high default risk and experience the highest increase in their default risk. Furthermore, the lowest returns $(-0.0755 \%$ per month) are realized by high default risk stocks that had the biggest decrease in their default risk. In addition, stocks in both of those portfolios are typically small and have high BM. Again, these results are consistent in sign and magnitude with those reported in Vassalou and Xing (2003).

The conclusions that emerge from Tables 3 and 5 are the following. Increases in default risk are followed by positive equity returns. The stocks that experience the highest returns are stocks that are high default risk, and whose default risk has increased the most over the past month. Those stocks are typically high BM and small 
in market capitalization. Interestingly, the stocks that realize the lowest returns are those that are again high default risk, high BM, and small in size, but with an important difference: they are the stocks whose default risk was most reduced during the past month. The results of Section 3 are perfectly consistent with the behavior of a rational economic agents.

In Section 4, we show why previous studies that used bond downgrades reached diametrically opposite conclusions from ours. In particular, we will relate our findings to theirs, and by doing that, we will provide new insights into the information content of changes in bond ratings.

\section{Default likelihood indicators, bond ratings and equity returns.}

Before we embark into an explanation of why our results in Section 3 are starkly different to those found in Holthausen and Leftwich (1985), Hand, Holthausen and Leftwich (1992), and Dichev and Piotroski (2001), it is important to show that their results can be replicated in our data-sample.

This is necessary for two reasons. First, it verifies that their findings are robust, and not necessarily specific to their data period or stock universe. Second, it shows that both our and their results can be obtained from the same data sample. It then becomes an issue of reconciling these diametrically opposite sets of results.

Table 6 reports the short- and long-run abnormal returns following bond downgrades. We focus only on downgrades, since they constitute the main result in the literature of equity returns following changes in bond ratings. 
As can be seen, it is indeed the case that equity returns following downgrades are negative in the months and years following the announcement of the event. Similarly to Dichev and Piotroski (2001), the returns we report are abnormal returns, in the sense that we have subtracted in each case the corresponding returns of portfolios with matching size and BM characteristics. To do that, we perform two independent sorts of stocks into size and BM quintiles, and create 25 size and BM portfolios from their intersection.

We report results for the whole sample, as well as for size, BM, and credit rating tertiles. By and large, the results are consistent with those in the literature, in the sense that equity abnormal returns following a downgrade are typically negative and generally statistically significant.

\subsection{The relation between DLI and changes in credit ratings.}

How can the results of Sections 3 and 4 coexist? To answer this question, we need to understand the relation between variations in DLI and credit rating changes.

\subsubsection{The pattern of DLI around downgrades}

In Figure 1, we plot the average DLI of all firms for a period of 6 years around the announcement dates of downgrades. The picture that emerges is quite revealing.

The DLI of the average firm increases at an increasing rate in the 36 months prior to the announcement of a downgrade. It reaches its peak at the announcement date. It then starts decreasing at almost the same rate at which it increased, until it approaches almost its 24-month pre-downgrade level in about 24 months! In other words, the graph 
of the average DLI has an inverted V-shape, with the peak being placed on the downgrades' announcement date.

The relation between DLI and downgrades becomes more transparent when we examine it for different credit rating groups. Those plots also appear in Figure 1. For firms with grade $\mathrm{C}$ bonds, the inverted $\mathrm{V}$-shape of the average DLI is even more pronounced. Default risk increases dramatically in the 12 months prior to the downgrade, but it is also reduced just as dramatically in the subsequent 12 months. For firms with grade B bonds, the pattern is somewhat less pronounced than that observed for the whole sample. Finally, for grade A bonds, there is no pattern at all. The graph of average DLI is basically a flat line.

The above results show that the evolution of DLI around a downgrade varies depending on the credit rating of the firm's bonds. When the credit rating is low, DLI increases substantially in the two years prior to the downgrade, and decreases almost equally much in the two-year period following the downgrade. As the credit rating of the firm increases, the above pattern becomes less and less pronounced.

A similar picture emerges when firms are classified into groups according to their market capitalization in Figure 2, and their BM in Figure 3. The inverted V-shape for DLI is more pronounced for small and high BM stocks. As Tables 3 to 5 revealed, these are also the stocks that exhibit the highest DLI and changes in DLI. As the size of the firms increases, or their BM decreases, the graphs of DLI around the downgrade announcement flatten out. 


\subsubsection{Implication of the evolution of DLI around downgrades for the computation of}

abnormal equity returns.

The results in the previous section show that DLI varies a lot around downgrades, and the variation is most pronounced for firms with low grade bonds, which are typically also small in size and have high BM. The implication of this finding is that when we calculate abnormal returns following a downgrade, it is not sufficient to adjust for the returns of portfolios with comparable size and BM. We also need to make sure that the portfolio whose returns we use to compute the abnormal returns of a firm's stocks matches the DLI of the firm at each point in time.

Table 7 reports raw (not risk-adjusted) returns for the same holding periods and categories of stocks as Table 6 . Note that the raw returns are not generally negative. It is the abnormal returns calculated following the Dichev and Piotroski (2001) methodology that are negative. Dichev and Piotroski report only abnormal returns in their study.

We calculate abnormal returns taking into account the variation in DLI, by using the following methodology. We create 25 size and BM portfolios from two independent sorts, as discussed in Section 4, in connection with the replication of the results in Dichev and Piotroski (2001). We then subdivide each of those portfolios into five portfolios according to DLI. In this manner, we obtain 125 portfolios which are used for calculating the abnormal returns for the different holding period horizons following the downgrades. ${ }^{9}$

It is apparent from Table 8, that the negative abnormal returns reported in Dichev and Piotroski (2001) largely disappear under our three-way adjustment. In particular, they are not statistically significant for all firms with downgrades in any of the holding-period

\footnotetext{
${ }^{9}$ We avoid performing three independent sorts according to size, BM, and DLI, in order to ensure that all portfolios have some stocks. Note that with independent sorts, it is possible that some portfolios will end up being empty.
} 
horizons examined, except the three-year horizon. Furthermore, when we examine abnormal returns for subgroups of stocks, significantly negative abnormal returns appear mainly in long horizons and for stocks that tend to be small in size, high BM, and with low grade debt. ${ }^{10}$

The existence of abnormal negative returns only in long horizons is at first puzzling. Dichev and Piotroski (2001) argue that the abnormal negative returns they observe in all horizons are due to investors' underreaction to the downgrade. An underreaction explanation seems plausible when abnormal returns are negative in short horizons, and decrease in magnitude as the horizon lengthens. In most cases, the effect of underreaction disappears within a year (see Chan, Jegadeesh and Lakonishock (1996) among others). In other words, the pattern observed in Table 8 is not consistent with the underreaction hypothesis.

We count the number of firms that have subsequent downgrades in the three-year period following the initial downgrade. We find that 1291 out of the 3095 firms with downgrades, experience at least a second downgrade within the subsequent three-year period. In other words, $41.71 \%$ of the firms are downgraded again after the initial downgrade.

We examine whether the significant negative abnormal returns observed in long horizons are due to subsequent downgrades. In particular, we re-compute abnormal returns for all horizons, using only the firms that did not experience subsequent downgrades in the three-year period following the initial downgrade. The results are reported in Table 9. Abnormal returns are now always around zero. Even in the two- to

\footnotetext{
${ }^{10}$ We divide firms into subgroups by their market capitalization (size), book-to-market ratio (BM) and preannouncement bond grade. Size and BM are those observed at the end of the month before the announcement of a downgrade.
} 
three-year horizons where abnormal returns are occasionally statistically significant, they are no longer economically significant. Therefore, long-horizon negative abnormal returns may be explained by the occurrence of subsequent downgrades during the threeyear period following the initial downgrade.

To understand the importance of adjusting abnormal returns for DLI, refer to Table 10. For each of the two adjustment methods, i.e., the one used in Dichev and Piotroski (2001), and the one used in Table 9, we report the average deviation in the BM, size, and DLI characteristics of the portfolio whose return is subtracted from the return of each individual stock.

Panel A reports the deviations for the method that uses portfolios constructed on the basis of only BM and size (as in Dichev and Piotroski (2001), and replicated here in Table 6). Panel B reports the results for the portfolios constructed on the basis of BM, size and DLI (as in Table 9). Recall that in the first case, only 25 portfolios are used for adjusting the returns of all stocks, whereas in the second case the number of portfolios is 125. Nevertheless, the difference we observe in the deviations of BM and size between the two methods are generally small. This is not the case for DLI. The average deviation in the DLI of the stock and the portfolio, across all stocks, is more than 2.5 times larger when returns are only adjusted by the returns of stocks with similar size and BM characteristics, than when they are adjusted by the returns of stocks with also similar DLI characteristics. Since DLI varies a lot around downgrades, taking this variation into account is important for the calculation of abnormal returns.

A three-way adjustment for the case of abnormal returns following upgrades produces little difference in the results known from previous studies. To conserve space, 
we do not report them here. The reason is that DLI does not vary significantly around upgrades, as Figure 4 reveals. There is some variation in DLI about 24 months following an upgrade in stocks with grade $\mathrm{C}$ stocks. However, this variation has to be interpreted with caution because there are only 16 grade $\mathrm{C}$ stocks with upgrades in our sample, as Table 1, Panel C shows. We therefore do not treat this variation as a reliable indication of a long-run reaction to the upgrade.

\subsubsection{What information do downgrades convey?}

The findings of the previous section reveal a link between variations in DLI and downgrades. This link can explain to a large extent the abnormal negative equity returns previously calculated in the literature. The explanation is that the previously reported abnormal returns were not adjusted for default risk. Once such an adjustment is performed, the negative returns largely disappear.

However, the results in the previous section also reveal that default risk decreases following a downgrade, and the decrease is larger, the higher the default risk of the firm. This observation begs the following question. If downgrades do not signal increased likelihood of default in the future, what is exactly their informational content? Furthermore, Figures 2 and 3 show that we can obtain roughly the same graphs of variation in DLI around downgrades by substituting classifications of stocks by credit ratings with classifications of stocks into size or BM tertiles. If those alternative classifications convey similar information, what is really the service that credit ratings provide to the investors' community? 
Based on the findings presented above, one can argue that downgrades have a disciplinary effect on the management of the company. Recall that although a firm's DLI at each point in time can be computed on the basis of publicly available information, it is not public information itself. Its computation or purchase from commercial providers is costly. Furthermore, it is likely to be available mainly to sophisticated investors, which may constitute a minority.

By contrast, credit ratings and downgrades are public information. In fact, changes in credit ratings constitute events. They are always accompanied by an explanation for the change in the credit rating, as well as by recommendations about what the firm can do to improve its prospects, in case its debt got downgraded. Companies often issue statements as responses to the downgrade announcements. When a company's debt falls within the speculative or junk bond categories, the management of the firm typically initiates a restructuring and cost-cutting plan. The main reason is that a credit rating change has implications for the firm's cost of borrowing. When its debt is downgraded, its interest payments increase. Furthermore, a downgrade affects the firm's ability to roll-over short-term debt. As a result, the firm may respond by retiring some of its debt.

Figure 5 plots annual changes in the book value of debt for a window of 6 years around the announcement of the downgrade. We plot annual rather than quarterly changes in the book value of debt, because firms vary in terms of the end of their fiscal years, and therefore, the date at which the book value of their debt becomes public information. Quarterly changes could make the results hard to interpret. The graph shows a general decrease in the rate of change of the book value of debt, for all rating 
categories, except possibly for those firms with A-rated bonds. Given that the initial rating in this case is so high, a downgrade may not affect significantly the cost of borrowing of those firms. Notice that the C-rated firms are those that drastically retire debt, since they are also the firms that are most negatively affected by a downgrade.

It is worthwhile to mention that the volatility of a firm's assets typically increases in the 12 months prior to the downgrade, and stays at relatively high levels for at least the 12 months following the downgrade. The increase is particularly steep following the announcement date of the downgrade, as Figure 6 shows. Since a firm's equity is a call option on the firm's assets, the increase in the volatility of assets increases the value of equity. The increased value of equity, together with the relative reduction in the amount of debt that the firm carries, leads to an increase in the ratio of equity to book value of debt following the downgrade. This result is presented in Figure 7.

When the equity to book value of debt ratio exhibits the above behavior, the ratio of the market value of assets to book value of debt does so too. This follows from the fact that the market value of assets is the sum of the market value of equity and the market value of debt. The graph of the ratio of market value of assets to book value of equity is presented in Figure 8. The net effect is that DLI goes down following a downgrade, since it is a function of the ratio of the market value of assets to the book value of debt, and the volatility of assets. ${ }^{11}$ Figures 5 to 8 help explain what leads to the changes in DLI around downgrades shown in Figure 1.

The argument that downgrades have a disciplinary effect on the management of firms is further supported by the different response of equity returns and DLI to upgrades.

\footnotetext{
${ }^{11}$ Recall that the market value of debt is not observed here, in contrast to the market value of equity, while the market value of assets and the volatility of assets are estimated following the procedures described in Section 1.
} 
Upgrades signal that the company is doing well and that its credit worthiness has improved. It is then rewarded with an upgrade which relaxes its borrowing constraints and provides more flexibility to its management. The DLI of the firm that got upgraded need not change significantly subsequent to the event, and it is not expected to. As a result, returns do not change subsequently to the upgrade.

The above explanation also implies the following. Despite the similarity of Figures 1, 2, and 3, credit ratings may provide a useful service to the investment community. By enforcing some action on the part of the firm's management, they implicitly try to set an upper limit to the firm's BM, and a lower bound to its market capitalization. By doing that, they also set some limits to the variation of DLI. Without public announcements of the state of credit worthiness of a firm, in the form of upgrades and downgrades, the firm's management could potentially follow more risky strategies for longer periods of time than they currently do.

Of course, the same information on the default risk of a firm, as that provided by a downgrade, can be obtained by investors and lending institutions through calculations of DLIs and close monitoring of a firm's BM and size characteristics. This, however, requires a higher level of sophistication in investment decisions, which can be obtained at a cost. This cost may be prohibitively high to small investors.

\section{Conclusions}

Previous studies document the existence of persistent abnormal equity returns following downgrades, and no equity reaction to upgrades. Since default risk is assumed to be higher after a downgrade, this finding is puzzling. In particular, it is inconsistent with the 
investment behavior of rational economic agents who require higher returns to hold riskier stocks.

In this study, we show that the above stylized fact is specific to the method used to compute abnormal returns, and specifically, to the fact that previous studies do not take into account the large variations in default risk around the date of the announcement of the downgrade.

We compute default likelihood indicators (DLIs) extracted from Merton's (1974) contingent claims model, and use them as a measure of default risk. We show that firms which experience large increases in their default risk earn higher subsequent returns than firms that experience large decreases in their default risk. Furthermore, a firm's likelihood of default varies a lot over time, especially when the firms are small, have high book-to-market (BM), and their debt is of relatively low grade.

Typically, DLIs increase significantly in the two- to three-year period prior to the downgrade. They reach their peak at the time of the downgrade announcement and start decreasing thereafter. The pace with which they decrease is approximately the same as that with which they increased in the first place. They reach almost their two- to threeyear pre-downgrade level in about two to three years. In other words, the evolution of DLI around downgrades follows an inverted V-shape.

This pattern implies that equity returns following a downgrade should be lower. In addition, it implies that the calculation of abnormal returns following downgrades should adjust for the observed variation in DLI, and not only for the size and BM characteristics of the firms, as was previously done. When returns are adjusted for DLI, as well as BM and size, the negative abnormal returns documented in the literature 
largely disappear, and they are observed mainly in long horizons. When in addition we take into account the occurrence of subsequent downgrades following the initial one, the significant negative abnormal returns in long horizons either disappear completely, or become economically insignificant.

The variation in DLI around upgrades is minimal, which explains the asymmetric response of equity returns to upgrades and downgrades, known from previous studies. Based on our results, we argue that credit ratings and downgrades have a disciplinary effect on the management of the company, which may constitute one of the important services that credit rating agencies provide to the investment community. In other words, they provide a monitoring service to investors essentially free of charge. This monitoring service could have been undertaken by the individual investors instead, but at a potentially prohibitively high cost for small investors. 


\section{References}

Black, F. and M. Scholes 1973, "The Pricing of Options and Corporate Liabilities," Journal of Political Economy, No 81, pp.637-659

Carhart , M. M., 1997, “On Persistence in Mutual Fund Performance," The Journal of Finance, 52, 1, 57-82.

Chan, L. K. C., N. Jegadeesh and J. Lakonishock, 1996, "Momentum Strategies," The Journal of Finance, 51, 1681-1713.

Crosbie, P.J. 1999, “Modeling Default Risk,” KMV LLC.

Dichev, Ilia D., J. D. Piotroski, 2001, "The Long-Run Stock Returns Following Bond Ratings Changes," Journal of Finance, 56, 1, 173-204.

Fama, Eugene F., and Kenneth R. French, 1993, "Common Risk Factors in the Returns on Bonds and Stocks," Journal of Financial Economics 33, 3-56.

Fama, Eugene F., and Kenneth R. French, 1996, "Multifactor Explanations of Asset Pricing Anomalies," Journal of Finance, LI, 1, 55-84.

Gibbons, M. R., S. A. Ross, and J. Shanken, 1989, "A Test of the Efficiency of a Given Portfolio," Econometrica, 57, 5, 1121-1152.

Hand, John R. M., Robert W. Holthausen, and Richard W. Leftwich, 1992, The Effect of Bond Rating Agency Announcements on Bond and Stock prices, Journal of Finance 47, 733-752.

Holthausen, Robert W., and Richard W. Leftwich, 1986, The Effect of Bond Rating Changes on Common Stock Prices, Journal of Financial Economics 17, 57-89.

Merton, R.C. 1974, "On the Pricing of Corporate Debt: The Risk Structure of Interest Rates,", Journal of Finance, 29, 449-470.

Newey, W., and K. West, 1987, “A Simple Positive-Definitive Heteroskedasticity and Autocorrelation Consistent Covariance Matrix", Econometrica.

Vassalou, M and Y. Xing, 2003, "Default Risk in Equity Returns," Journal of Finance, forthcoming.

Weinstein, M., 1977, "The Effect of a Rating Change Announcement on Bond Price," Journal of Financial Economics, 5, 329-350.

Zonana, V. and D. Hertzberg, 1981, “The Rating Game,” Wall Street Journal, Nov. 2. 
Table 1: Summary Statistics of Bond Ratings

Panel A: Number of Downgrades and Upgrades by Year

\begin{tabular}{|c|c|c|c|c|}
\hline & Up & Down & Firms in Moody's & Firms with DLI \\
\hline 1971 & 4 & 14 & 302 & 1284 \\
\hline 1972 & 7 & 3 & 213 & 1451 \\
\hline 1973 & 13 & 8 & 177 & 2194 \\
\hline 1974 & 17 & 13 & 262 & 2348 \\
\hline 1975 & 20 & 17 & 333 & 2463 \\
\hline 1976 & 11 & 9 & 266 & 2711 \\
\hline 1977 & 13 & 24 & 251 & 2756 \\
\hline 1978 & 18 & 13 & 233 & 2754 \\
\hline 1979 & 12 & 21 & 236 & 2746 \\
\hline 1980 & 19 & 32 & 383 & 2718 \\
\hline 1981 & 29 & 34 & 358 & 2738 \\
\hline 1982 & 23 & 115 & 1384 & 2831 \\
\hline 1983 & 67 & 110 & 534 & 2838 \\
\hline 1984 & 82 & 97 & 596 & 3053 \\
\hline 1985 & 64 & 135 & 766 & 3101 \\
\hline 1986 & 57 & 226 & 1060 & 3048 \\
\hline 1987 & 72 & 144 & 952 & 3103 \\
\hline 1988 & 78 & 177 & 859 & 3177 \\
\hline 1989 & 78 & 210 & 887 & 3071 \\
\hline 1990 & 62 & 298 & 924 & 2952 \\
\hline 1991 & 63 & 225 & 1041 & 2923 \\
\hline 1992 & 98 & 138 & 1099 & 2967 \\
\hline 1993 & 123 & 97 & 1287 & 3059 \\
\hline 1994 & 129 & 88 & 1141 & 3255 \\
\hline 1995 & 119 & 114 & 1371 & 3362 \\
\hline 1996 & 172 & 100 & 1587 & 3472 \\
\hline 1997 & 166 & 140 & 1957 & 3703 \\
\hline 1998 & 161 & 222 & 2335 & 3662 \\
\hline 1999 & 162 & 271 & 1923 & 3384 \\
\hline Total & 1939 & 3095 & & \\
\hline
\end{tabular}

Panel B: Equity Characteristics of Bond issuers

\begin{tabular}{lcccccc}
\hline \hline & Mean(BM) & Std(BM) & Mean(size) & Std(size) & Mean(DLI) & Std(DLI) \\
Grade A & 0.6653 & 0.3540 & 7.9872 & 1.5038 & 0.0892 & 0.4705 \\
Grade B & 0.7785 & 0.7492 & 6.4958 & 1.5707 & 4.8130 & 14.1795 \\
Grade C & 2.4002 & 3.0086 & 4.2412 & 1.7136 & 46.5602 & 43.5564 \\
\hline \hline
\end{tabular}

Panel C: Number of Downgrades and Upgrades by Ratings

\begin{tabular}{ccccccccc}
\hline \hline & Up & Down & & Up & Down & & Up & Down \\
Grade A & 749 & 616 & Small & 349 & 1167 & Low BM & 888 & 607 \\
Grade B & 1174 & 1689 & Medium & 832 & 1029 & Medium & 762 & 1103 \\
Grade C & 16 & 790 & Big & 758 & 898 & High BM & 290 & 1386 \\
Total & 1939 & 3095 & & 1939 & 3095 & & 1939 & 3095 \\
\hline \hline
\end{tabular}


Note: Panel A reports the number of upgrades and downgrades each year. It also reports the number of firms covered by Moody's database, as well as the number of firms for which sufficient information was available in the databases to compute DLIs. Panel B reports the average equity characteristics by Moody's broad credit rating category. Grade A includes firms with debt ratings of A, AA and AAA. Similarly, Grade B includes firms with credit ratings that start with $\mathrm{B}$, and Grade $\mathrm{C}$ includes firms whose debt has a credit rating that starts with $\mathrm{C}$. In Panel $\mathrm{C}$, we report the number of downgrades and upgrades by three alternative groupings of firms: credit ratings, size, and book-to-market (BM). 
Table 2: Summary Statistics on DLI

Panel A: Summary statistics on DLI and CDLI

\begin{tabular}{lccccc}
\hline \hline & Mean & Std & Skew & Kurt & Auto \\
DLI & 4.2261 & 13.0376 & 4.1304 & 18.4083 & 0.9189 \\
CDLI & 0.0950 & 5.1118 & 0.6149 & 37.7116 & -0.0932 \\
\hline \hline
\end{tabular}

Panel B: Summary Statistics for Size Portfolios

\begin{tabular}{lccccc}
\hline \hline & Small 1 & 2 & 3 & 4 & Big 5 \\
RET & 2.1240 & 1.1622 & 1.2162 & 1.2892 & 1.2225 \\
CDLI & 0.3524 & 0.0410 & 0.0127 & -0.0046 & -0.0068 \\
DLI & 11.6100 & 4.9351 & 2.5953 & 1.3932 & 0.6141 \\
\hline \hline
\end{tabular}

Panel C: Summary Statistics for BM Portfolios

\begin{tabular}{lccccc}
\hline \hline & Low BM & 2 & 3 & 4 & High BM \\
RET & 1.0233 & 1.1047 & 1.2307 & 1.4892 & 2.1586 \\
CDLI & -0.0653 & -0.0599 & -0.0319 & -0.0216 & 0.5715 \\
DLI & 1.5062 & 1.6334 & 2.2206 & 3.6598 & 12.0360 \\
\hline \hline
\end{tabular}

Note: DLI denotes the default likelihood indicator. CDLI is the change in the DLI. Mean, Std, Skew, Kurt and Auto refer to the mean, standard deviation, skewness, kurtosis and autocorrelation at lag 1 respectively. Panel B and Panel C report summary statistics for size and book-to-market (BM) quintile portfolios. RET is the equally-weighted average return expressed in percentage terms. Our sample covers the period from 1971.1 to 1999.12. 
Table 3: Portfolios Sorted on Changes in Default Risk (DLI)

Panel A: Portfolios sorted on the basis of past one-month's CDLI

\begin{tabular}{|c|c|c|c|c|c|c|c|c|c|c|c|c|}
\hline $\begin{array}{l}\text { Portfolios } \\
\text { (formation, holding) }\end{array}$ & (Low) & 2 & 3 & 4 & 5 & 6 & 7 & 8 & 9 & (High) & High-Lov & t-value \\
\hline$(1,1)$ & 0.28 & 1.28 & 1.49 & 1.33 & 1.33 & 1.24 & 1.29 & 1.46 & 1.56 & 2.45 & 2.17 & 10.12 \\
\hline$(1,3)$ & 0.93 & 1.44 & 1.54 & 1.43 & 1.32 & 1.31 & 1.29 & 1.39 & 1.38 & 1.60 & 0.66 & 5.94 \\
\hline$(1,6)$ & 1.21 & 1.45 & 1.48 & 1.39 & 1.31 & 1.33 & 1.30 & 1.36 & 1.35 & 1.36 & 0.15 & 2.01 \\
\hline$(1,9)$ & 1.35 & 1.45 & 1.42 & 1.33 & 1.29 & 1.31 & 1.29 & 1.34 & 1.34 & 1.37 & 0.02 & 0.36 \\
\hline$(1,12)$ & 1.42 & 1.46 & 1.40 & 1.32 & 1.28 & 1.27 & 1.24 & 1.29 & 1.31 & 1.39 & -0.03 & -0.75 \\
\hline$(1,18)$ & 1.41 & 1.42 & 1.33 & 1.26 & 1.24 & 1.24 & 1.23 & 1.28 & 1.34 & 1.42 & 0.00 & 0.12 \\
\hline$(1,24)$ & 1.41 & 1.38 & 1.30 & 1.24 & 1.22 & 1.22 & 1.21 & 1.26 & 1.33 & 1.40 & 0.00 & -0.10 \\
\hline
\end{tabular}

Panel B: Properties of 10 Deciles of Holding Period=1 Month

\begin{tabular}{lcccccccccc}
\hline \hline Average Size & 2.75 & 3.57 & 4.28 & 4.89 & 5.39 & 5.44 & 4.96 & 4.28 & 3.49 & 2.64 \\
Average BM & 1.43 & 1.01 & 0.83 & 0.75 & 0.69 & 0.69 & 0.74 & 0.84 & 1.06 & 1.61 \\
Average CDLI & -6.78 & -0.67 & -0.15 & -0.04 & -0.01 & 0.01 & 0.05 & 0.17 & 0.76 & 7.50 \\
Turnover & 0.70 & 0.80 & 0.82 & 0.82 & 0.75 & 0.72 & 0.82 & 0.83 & 0.81 & 0.69 \\
\hline \hline
\end{tabular}

Panle C: Returns of Portfolios Held for One-Month

\begin{tabular}{|c|c|c|c|c|c|c|c|c|c|c|c|c|}
\hline $\begin{array}{l}\text { Portfolios } \\
\text { (formation, holding) }\end{array}$ & (Low) & 2 & 3 & 4 & 5 & 6 & 7 & 8 & 9 & (High) & High-Low & t-value \\
\hline$(3,1)$ & 0.77 & 1.41 & 1.51 & 1.58 & 1.43 & 1.22 & 1.23 & 1.27 & 1.33 & 2.10 & 1.33 & 5.75 \\
\hline$(6,1)$ & 1.26 & 1.49 & 1.51 & 1.45 & 1.37 & 1.34 & 1.29 & 1.24 & 1.28 & 1.74 & 0.48 & 2.21 \\
\hline$(9,1)$ & 1.56 & 1.61 & 1.45 & 1.44 & 1.40 & 1.30 & 1.32 & 1.22 & 1.21 & 1.64 & 0.08 & 0.35 \\
\hline$(12,1)$ & 1.78 & 1.68 & 1.66 & 1.49 & 1.36 & 1.27 & 1.23 & 1.14 & 1.06 & 1.53 & -0.25 & -1.17 \\
\hline$(18,1)$ & 2.02 & 1.93 & 1.75 & 1.67 & 1.66 & 1.65 & 1.63 & 1.58 & 1.51 & 2.04 & 0.03 & 0.12 \\
\hline$(24,1)$ & 2.03 & 1.83 & 1.61 & 1.63 & 1.79 & 1.72 & 1.68 & 1.64 & 1.49 & 2.10 & 0.07 & 0.29 \\
\hline
\end{tabular}

Note: Panel A reports equally-weighted returns of portfolios sorted on the basis of changes in default risk (CDLI) over the past month and held for alternative holding periods. "Formation" refers to formation period and "holding" refers to the holding period. The portfolios in the first column of the table are numbered with two digits. The first digit refers to the formation period, whereas the second one refers to the holding period of the portfolio. For instance, portfolio $(1,1)$ is the portfolio formed on the basis of changes in the default likelihood indicator (CDLI) over the past month, and which is then held for one month. Similarly, portfolio $(24,1)$ is the portfolio formed on the basis of CDLI over the past 24 months, which is then held for one month. In the first row of Panels $\mathrm{A}$ and $\mathrm{C}$, portfolios are numbered by a single digit which refers to the CDLI. Portfolio 1 is the portfolio with the lowest CDLI and portfolio 10 is the portfolio with the highest CDLI. Panel B reports the characteristics of the portfolios held for one month. "Size" denotes market capitalization, and "BM" the book-to-market ratio of the firm. Panel C reports equally-weighted one-month-holding- period returns for portfolios formed on the basis of CDLI, calculated over alternative time periods (formation periods). T-values are computed from Newey-West standard errors. The sample covers the period from 1971:1 to1999:12. 
Table 4: Risk-Adjusted Excess Returns

\begin{tabular}{ccccccc}
\hline \hline & CAPM & \multicolumn{3}{c}{ FF3 } & \multicolumn{3}{c}{ FF3+WML } \\
1 & -0.9094 & t-value & a & t-value & a & t-value \\
2 & 0.0297 & $(0.1280)$ & -0.1366 & $(-1.2018)$ & 0.0501 & $(0.4110)$ \\
3 & 0.2832 & $(1.5787)$ & 0.2394 & $(3.0380)$ & 0.2532 & $(2.6456)$ \\
4 & 0.1725 & $(1.1302)$ & 0.1189 & $(1.3444)$ & 0.1537 & $(1.5225)$ \\
5 & 0.1853 & $(1.5576)$ & 0.1151 & $(1.7109)$ & 0.1382 & $(1.9132)$ \\
6 & 0.0737 & $(0.5352)$ & -0.0374 & $(-0.4541)$ & 0.0268 & $(0.2909)$ \\
7 & 0.0768 & $(0.5020)$ & -0.0080 & $(-0.1192)$ & 0.0807 & $(0.9255)$ \\
8 & 0.2015 & $(1.0277)$ & 0.0474 & $(0.5348)$ & 0.2451 & $(2.2852)$ \\
9 & 0.2903 & $(1.2312)$ & 0.0749 & $(0.6017)$ & 0.4230 & $(3.5442)$ \\
10 & 1.1273 & $(3.3588)$ & 0.8241 & $(4.1184)$ & 1.5301 & $(7.6129)$ \\
Diff & 2.0367 & $(10.5388)$ & 2.0009 & $(11.4419)$ & 2.2695 & $(11.3365)$ \\
& & & & & & \\
GRS & 22.8479 & & 24.3204 & & 25.1579 & \\
p-value & 0.0000 & & 0.0000 & & 0.0000 & \\
\hline \hline
\end{tabular}

Note: This table reports the alphas ( $\alpha$ 's) and t-values from time series regressions of portfolio returns on the factors of alternative asset pricing models. The portfolio returns are those of portfolios of the type $(1,1)$, sorted according to CDLI. In other words, portfolio 1 is the portfolio with stocks that experienced the lowest changes in DLI over the past month, and which is held for one month. Similarly, portfolio 10 is the portfolio with the biggest changes in DLI over the past month, which is also held for only one month. FF3 refers to the Fama French (1993) three-factor model. FF3+WML refers to the Carhart (1997) four-factor model where WML is a 12-month momentum factor. GRS refers to the Gibbons, Ross, and Shanken statistic of joint significance of the alphas across the 10 portfolios. T-values are calculated from Newey-West standard errors. The sample period is from 1971:1 to 1999:12. 
TABLE 5: Changes in Default Risk by Default Category

Panel A: Average Returns

\begin{tabular}{lccccccc}
\hline \hline & Low CDLI & 2 & 3 & 4 & High CDL & High-Low & t-value \\
High DLI & -0.0755 & 1.1362 & 1.9323 & 2.4242 & 3.5756 & 3.6511 & $(16.0436)$ \\
2 & 0.4492 & 1.1248 & 1.4297 & 1.6182 & 1.7391 & 1.2899 & $(8.3080)$ \\
3 & 1.0787 & 1.4562 & 1.4016 & 1.4536 & 1.5891 & 0.5104 & $(4.2547)$ \\
4 & 1.2134 & 1.2702 & 1.4423 & 1.4493 & 1.4927 & 0.2793 & $(2.5503)$ \\
Low DLI & 1.1480 & 1.1364 & 1.1304 & 1.1289 & 1.3574 & 0.2095 & $(2.1435)$ \\
\hline \hline
\end{tabular}

Panel B: Average DLI

\begin{tabular}{lccccc}
\hline \hline & Low CDLI & 2 & 3 & 4 & High CDLI \\
High DLI & -11.1125 & -1.9307 & 0.9176 & 3.7886 & 13.5890 \\
2 & -3.4633 & -0.5476 & 0.0257 & 0.4112 & 1.2650 \\
3 & -0.8239 & -0.0914 & -0.0071 & 0.0412 & 0.1236 \\
4 & -0.1547 & -0.0073 & -0.0010 & 0.0019 & 0.0071 \\
Low DLI & -0.0279 & 0.0000 & 0.0000 & 0.0000 & 0.0000 \\
\hline \hline
\end{tabular}

Panel C: Average Size

\begin{tabular}{lccccc}
\hline \hline & Low CDLI & 2 & 3 & 4 & High CDLI \\
High DLI & 2.3810 & 2.5960 & 2.7357 & 2.6555 & 2.3485 \\
2 & 3.2042 & 3.4574 & 3.6548 & 3.6294 & 3.4065 \\
3 & 3.8942 & 4.1553 & 4.3722 & 4.3722 & 4.1559 \\
4 & 4.5395 & 4.7912 & 5.0490 & 5.0280 & 4.7844 \\
Low DLI & 5.1760 & 5.4812 & 5.8106 & 5.7898 & 5.4132 \\
\hline \hline
\end{tabular}

Panel D: Average BM

\begin{tabular}{lccccc}
\hline \hline & Low CDLI & 2 & 3 & 4 & High CDLI \\
High DLI & 1.7295 & 1.5941 & 1.5009 & 1.5640 & 1.8816 \\
2 & 1.0958 & 1.0082 & 0.9604 & 0.9624 & 1.0417 \\
3 & 0.8723 & 0.8352 & 0.8164 & 0.8153 & 0.8411 \\
4 & 0.7669 & 0.7543 & 0.7410 & 0.7385 & 0.7633 \\
Low DLI & 0.6959 & 0.6730 & 0.6053 & 0.6139 & 0.6844 \\
\hline \hline
\end{tabular}

Note: From 1971.1-1999.12, at the beginning of each month, stocks are sorted into 5 portfolios on the basis of their DLI in the previous month. Within each portfolio, stocks are then sorted into 5 portfolios, based on past month's changes in DLI (CDLI). Equally weighted average portfolio returns are reported in percentage terms. "High-Low" is the return difference between the highest and lowest CDLI portfolios within each default risk quintile. T-values are calculated from Newey-West standard errors. The sample period is from 1971:1 to 1999:12. 
Table 6: Abnormal Returns Following Bond Downgrade- Adjusted by Size and Book-to-Market

\begin{tabular}{|c|c|c|c|c|c|c|}
\hline All & $\begin{array}{l}1-\text { month } \\
-0.8460 \\
(-2.0336)\end{array}$ & $\begin{array}{c}\text { 3-month } \\
-3.3443 \\
(-5.1884)\end{array}$ & $\begin{array}{l}\text { 6-month } \\
-4.2027 \\
(-4.7018)\end{array}$ & $\begin{array}{l}1 \text {-st year } \\
-7.8916 \\
(-5.8908)\end{array}$ & $\begin{array}{c}\text { 2-nd year } \\
-5.1395 \\
(-3.9601)\end{array}$ & $\begin{array}{c}\text { 3-rd year } \\
-8.5022 \\
(-6.1031)\end{array}$ \\
\hline Grade A & $\begin{array}{c}-0.3323 \\
(-0.8667)\end{array}$ & $\begin{array}{c}-0.5758 \\
(-0.8287)\end{array}$ & $\begin{array}{c}-1.0797 \\
(-1.0958)\end{array}$ & $\begin{array}{c}-3.0000 \\
(-2.2255)\end{array}$ & $\begin{array}{c}-4.3575 \\
(-2.5039)\end{array}$ & $\begin{array}{c}-5.3410 \\
(-2.9274)\end{array}$ \\
\hline Grade B & $\begin{array}{c}-0.9652 \\
(-2.0250)\end{array}$ & $\begin{array}{c}-3.7019 \\
(-4.7483)\end{array}$ & $\begin{array}{c}-5.0828 \\
(-4.5309)\end{array}$ & $\begin{array}{l}-10.0440 \\
(-5.4974)\end{array}$ & $\begin{array}{c}-6.2635 \\
(-3.5882)\end{array}$ & $\begin{array}{c}-8.7730 \\
(-4.9127)\end{array}$ \\
\hline Grade C & $\begin{array}{c}-1.5575 \\
(-0.5872)\end{array}$ & $\begin{array}{c}-8.8350 \\
(-2.4154)\end{array}$ & $\begin{array}{c}-7.6304 \\
(-1.5957)\end{array}$ & $\begin{array}{c}-8.7690 \\
(-1.4459)\end{array}$ & $\begin{array}{c}-0.7550 \\
(-0.1427)\end{array}$ & $\begin{array}{l}-15.5690 \\
(-2.3471)\end{array}$ \\
\hline Small & $\begin{array}{c}3.0460 \\
(0.6078)\end{array}$ & $\begin{array}{c}-9.7529 \\
(-1.4619)\end{array}$ & $\begin{array}{c}-1.5922 \\
(-0.1472)\end{array}$ & $\begin{array}{c}1.9080 \\
(0.1505)\end{array}$ & $\begin{array}{l}-14.0630 \\
(-1.1977)\end{array}$ & $\begin{array}{l}-27.8580 \\
(-2.2138)\end{array}$ \\
\hline Medium & $\begin{array}{c}0.0040 \\
(0.0025)\end{array}$ & $\begin{array}{c}-5.3027 \\
(-2.1164)\end{array}$ & $\begin{array}{c}-8.2426 \\
(-2.4524)\end{array}$ & $\begin{array}{c}-9.2847 \\
(-1.9739)\end{array}$ & $\begin{array}{c}-0.9370 \\
(-0.2366)\end{array}$ & $\begin{array}{l}-15.5730 \\
(-3.1920)\end{array}$ \\
\hline Big & $\begin{array}{c}-1.2028 \\
(-3.1375)\end{array}$ & $\begin{array}{c}-2.9704 \\
(-4.9630)\end{array}$ & $\begin{array}{c}-4.1344 \\
(-5.0817)\end{array}$ & $\begin{array}{c}-8.5989 \\
(-6.3982)\end{array}$ & $\begin{array}{c}-5.3580 \\
(-3.9380)\end{array}$ & $\begin{array}{c}-6.5830 \\
(-4.8235)\end{array}$ \\
\hline High BM & $\begin{array}{c}-1.1618 \\
(-1.8969)\end{array}$ & $\begin{array}{c}-3.8345 \\
(-4.0648)\end{array}$ & $\begin{array}{c}-5.3542 \\
(-4.2842)\end{array}$ & $\begin{array}{c}-8.6700 \\
(-4.5432)\end{array}$ & $\begin{array}{c}-4.5833 \\
(-2.5880)\end{array}$ & $\begin{array}{c}-8.2110 \\
(-4.3545)\end{array}$ \\
\hline Medium BM & $\begin{array}{c}-0.6184 \\
(-1.2916)\end{array}$ & $\begin{array}{c}-2.6222 \\
(-3.0541)\end{array}$ & $\begin{array}{c}-3.4912 \\
(-2.5005)\end{array}$ & $\begin{array}{c}-6.7940 \\
(-3.3674)\end{array}$ & $\begin{array}{c}-5.1976 \\
(-2.3378)\end{array}$ & $\begin{array}{c}-7.8230 \\
(-3.8120)\end{array}$ \\
\hline Low BM & $\begin{array}{c}-0.1464 \\
(-0.1103) \\
\end{array}$ & $\begin{array}{c}-4.1817 \\
(-2.2456) \\
\end{array}$ & $\begin{array}{c}-4.3086 \\
(-1.7032) \\
\end{array}$ & $\begin{array}{l}-11.2460 \\
(-2.7316) \\
\end{array}$ & $\begin{array}{c}-5.9636 \\
(-1.5624) \\
\end{array}$ & $\begin{array}{l}-12.6540 \\
(-2.4554) \\
\end{array}$ \\
\hline
\end{tabular}

Note: This table reports the long term abnormal stock returns following Moody's downgrade announcements. Average cumulative abnormal returns (CAR) are computed for different horizons. Firm specific CARs are the sums of the difference in the log monthly returns of the firm and a benchmark portfolio with similar size and book-tomarket characteristics. Twenty-five benchmark portfolios are constructed from the intersection of two independent sorts of stocks into five size, and five BM portfolios. This methodology for calculating abnormal returns is the same as that used in Dichev and Piotroski (2001). The CARs reported in the table are the average (mean) cumulative abnormal returns of the stocks that fall within the categories we examine. 
Table 7: The Long-Term Raw Return Following Bond Downgrade

\begin{tabular}{|c|c|c|c|c|c|c|}
\hline All & $\begin{array}{c}1 \text {-month } \\
0.5431 \\
(1.2077)\end{array}$ & $\begin{array}{c}\text { 3-month } \\
0.7580 \\
(1.0207)\end{array}$ & $\begin{array}{c}\text { 6-month } \\
3.5637 \\
(3.4170)\end{array}$ & $\begin{array}{c}1 \text {-st year } \\
7.4568 \\
(5.0765)\end{array}$ & $\begin{array}{c}\text { 2-nd year } \\
8.9561 \\
(6.4933)\end{array}$ & $\begin{array}{c}\text { 3-rd year } \\
5.7313 \\
(3.8484)\end{array}$ \\
\hline Grade A & $\begin{array}{c}1.3189 \\
(2.7963)\end{array}$ & $\begin{array}{c}4.0181 \\
(4.7721)\end{array}$ & $\begin{array}{c}8.6210 \\
(7.0293)\end{array}$ & $\begin{array}{l}13.9890 \\
(9.1994)\end{array}$ & $\begin{array}{l}10.9170 \\
(5.9538)\end{array}$ & $\begin{array}{l}10.9770 \\
(5.6839)\end{array}$ \\
\hline Grade B & $\begin{array}{c}0.3162 \\
(0.6072)\end{array}$ & $\begin{array}{c}0.4473 \\
(0.4888)\end{array}$ & $\begin{array}{c}2.6019 \\
(1.9546)\end{array}$ & $\begin{array}{c}5.4270 \\
(2.7059)\end{array}$ & $\begin{array}{c}7.5580 \\
(4.0878)\end{array}$ & $\begin{array}{c}5.4680 \\
(2.8919)\end{array}$ \\
\hline Grade C & $\begin{array}{c}-0.3910 \\
(-0.1295)\end{array}$ & $\begin{array}{c}-7.3087 \\
(-1.6821)\end{array}$ & $\begin{array}{c}-5.8599 \\
(-1.0463)\end{array}$ & $\begin{array}{c}0.3590 \\
(0.0514)\end{array}$ & $\begin{array}{l}11.9080 \\
(1.9526)\end{array}$ & $\begin{array}{c}-8.7720 \\
(-1.1343)\end{array}$ \\
\hline Small & $\begin{array}{c}4.9477 \\
(0.9218)\end{array}$ & $\begin{array}{c}-7.7931 \\
(-1.0079)\end{array}$ & $\begin{array}{c}6.2631 \\
(0.5139)\end{array}$ & $\begin{array}{l}15.6790 \\
(1.1688)\end{array}$ & $\begin{array}{c}-3.4370 \\
(-0.2518)\end{array}$ & $\begin{array}{l}-20.2180 \\
(-1.6368)\end{array}$ \\
\hline Medium & $\begin{array}{c}1.1555 \\
(0.7239)\end{array}$ & $\begin{array}{c}-1.7836 \\
(-0.6548)\end{array}$ & $\begin{array}{c}-2.9298 \\
(-0.7645)\end{array}$ & $\begin{array}{c}2.2120 \\
(0.4448)\end{array}$ & $\begin{array}{c}9.7306 \\
(2.3082)\end{array}$ & $\begin{array}{c}-4.2170 \\
(-0.8059)\end{array}$ \\
\hline Big & $\begin{array}{c}0.2748 \\
(0.6530)\end{array}$ & $\begin{array}{c}1.5382 \\
(2.2094)\end{array}$ & $\begin{array}{c}4.7165 \\
(4.9225)\end{array}$ & $\begin{array}{c}8.1810 \\
(5.6114)\end{array}$ & $\begin{array}{c}9.2320 \\
(6.5411)\end{array}$ & $\begin{array}{c}8.5280 \\
(5.8816)\end{array}$ \\
\hline High BM & $\begin{array}{c}0.4746 \\
(0.7312)\end{array}$ & $\begin{array}{c}0.8887 \\
(0.8350)\end{array}$ & $\begin{array}{c}3.6239 \\
(2.5110)\end{array}$ & $\begin{array}{c}8.6236 \\
(4.2203)\end{array}$ & $\begin{array}{c}9.8416 \\
(5.3907)\end{array}$ & $\begin{array}{c}6.2063 \\
(3.0476)\end{array}$ \\
\hline Medium BM & $\begin{array}{c}0.4286 \\
(0.7909)\end{array}$ & $\begin{array}{c}0.8742 \\
(0.8564)\end{array}$ & $\begin{array}{c}3.8075 \\
(2.2940)\end{array}$ & $\begin{array}{c}7.2486 \\
(3.2164)\end{array}$ & $\begin{array}{c}7.0425 \\
(2.9561)\end{array}$ & $\begin{array}{c}6.7126 \\
(3.1253)\end{array}$ \\
\hline Low BM & $\begin{array}{c}1.2247 \\
(0.8516)\end{array}$ & $\begin{array}{c}-0.2734 \\
(-0.1296)\end{array}$ & $\begin{array}{c}2.5874 \\
(0.8819)\end{array}$ & $\begin{array}{c}1.5325 \\
(0.3606)\end{array}$ & $\begin{array}{c}9.0822 \\
(2.1062)\end{array}$ & $\begin{array}{c}0.5131 \\
(0.0980)\end{array}$ \\
\hline
\end{tabular}

Note: This table reports the long term raw (unadjusted for risk) stock returns following Moody's downgrade announcements. Cumulative returns for a stock are computed for different horizons as the sum of the log monthly returns of the stock. The returns reported are the average cumulative returns of stocks that fall within the categories examined. 
Table 8: Abnormal Return Following Downgrade - Adjusted for Size, BooktoMarket, and default Risk (DLI)

\begin{tabular}{lcccccc}
\hline \hline & 1 -month & 3 -month & 6 -month & 1 -st year & 2-nd year & 3-rd year \\
All & -0.2775 & -1.0109 & -1.4168 & -1.4893 & -1.2487 & -5.7926 \\
& $(-0.6052)$ & $(-1.4549)$ & $(-1.4136)$ & $(-1.1293)$ & $(-0.9135)$ & $(-4.4818)$ \\
Grade A & & & & & & \\
& 0.1443 & 0.2052 & 0.7855 & 0.3541 & -1.8005 & -2.2031 \\
Grade B & $(0.3033)$ & $(0.2459)$ & $(0.6427)$ & $(0.2240)$ & $(-1.0184)$ & $(-1.2610)$ \\
& -0.5829 & -1.1177 & -1.8158 & -3.4344 & -1.7867 & -7.5508 \\
Grade C & $(-1.0683)$ & $(-1.3441)$ & $(-1.4921)$ & $(-1.9650)$ & $(-1.0227)$ & $(-4.5131)$ \\
& 0.5005 & -4.7569 & -6.6089 & 6.6343 & 4.9901 & -5.6812 \\
& $(0.1444)$ & $(-0.9652)$ & $(-0.9618)$ & $(0.9153)$ & $(0.6159)$ & $(-0.8038)$ \\
Small & & & & & & \\
& & & & & & \\
Medium & -0.0640 & -1.6308 & -2.3890 & -0.6651 & 0.0489 & -9.2192 \\
& $(-0.0633)$ & $(-1.1196)$ & $(-1.1381)$ & $(-0.2572)$ & $(0.0179)$ & $(-3.8018)$ \\
Big & -0.6258 & -1.5784 & -3.2517 & -4.9309 & -5.9516 & -5.2166 \\
& $(-1.2268)$ & $(-1.7744)$ & $(-2.3083)$ & $(-2.3779)$ & $(-2.7331)$ & $(-2.4626)$ \\
& -0.1755 & 0.4176 & 1.8558 & 1.1952 & 2.1961 & -1.9524 \\
& $(-0.2830)$ & $(0.4141)$ & $(1.4348)$ & $(0.6384)$ & $(1.2607)$ & $(-1.0006)$ \\
High BM & & & & & & \\
& -0.1831 & -1.1219 & -2.5075 & -1.5458 & -4.5696 & -4.8325 \\
Medium BM & $(-0.2386)$ & $(-1.0231)$ & $(-1.6346)$ & $(-0.7788)$ & $(-2.1780)$ & $(-2.4405)$ \\
& -0.5582 & -0.7398 & -0.9902 & -3.9624 & 1.0397 & -5.6749 \\
Low BM & $(-0.8763)$ & $(-0.7038)$ & $(-0.6555)$ & $(-1.9571)$ & $(0.5015)$ & $(-2.8679)$ \\
& 0.0841 & -1.2889 & 1.4459 & 4.8971 & 4.9930 & -9.5457 \\
& $(0.1263)$ & $(-0.9343)$ & $(0.5969)$ & $(1.5032)$ & $(1.6214)$ & $(-3.1904)$ \\
\hline \hline
\end{tabular}

Note: This table reports the long term abnormal stock returns following Moody's downgrade announcements. Average cumulative abnormal returns (CAR) are computed for different horizons. Firm specific CARs are the sums of the difference in the log monthly returns of the firm and a benchmark portfolio with similar size, book-to-market, and default risk (DLI) characteristics. Twenty-five benchmark portfolios are constructed from the intersection of two independent sorts of stocks into five size, and five BM portfolios. Subsequently, each of the twenty-five portfolios is subdivided into five portfolios according to the DLI of the stocks. This procedure gives rise to the construction of 125 benchmark portfolios. The CARs reported in the table are the average (mean) cumulative abnormal returns of the stocks that fall within the categories we examine. 
Table 9: Abnormal Returns Following Downgrades for firms with no subsequent downgrades

Returns Adjusted for Size, Book-to-Market, and Default Risk (DLI)

\begin{tabular}{lcccccc}
\hline \hline & 1 -month & 3 -month & 6 -month & 1-st year & 2-nd year & 3-rd year \\
All & -0.0012 & 0.0206 & 0.0165 & 0.0882 & 0.0881 & -0.0220 \\
& $(-0.1369)$ & $(1.4466)$ & $(0.7223)$ & $(3.5100)$ & $(2.8063)$ & $(-0.7794)$ \\
Grade A & & & & & & \\
& 0.0058 & 0.0293 & 0.0322 & 0.0629 & 0.0394 & 0.0400 \\
Grade B & $(0.5667)$ & $(1.9572)$ & $(1.1086)$ & $(1.9935)$ & $(1.6374)$ & $(1.3571)$ \\
& -0.0012 & 0.0231 & 0.0352 & 0.0765 & 0.0611 & -0.0988 \\
Grade C & $(-0.1255)$ & $(1.3964)$ & $(1.4616)$ & $(2.2532)$ & $(1.7225)$ & $(-3.4901)$ \\
& -0.0102 & 0.0013 & -0.0653 & 0.1594 & 0.2396 & 0.1507 \\
& $(-0.2879)$ & $(0.0235)$ & $(-0.7092)$ & $(2.1394)$ & $(1.9185)$ & $(1.3150)$ \\
Small & & & & & & \\
& & & & & & \\
Medium & -0.0119 & -0.0143 & -0.0246 & 0.1414 & 0.2109 & 0.0206 \\
& $(-0.5760)$ & $(-0.4286)$ & $(-0.4435)$ & $(2.5090)$ & $(2.6305)$ & $(0.2921)$ \\
Big & 0.0044 & 0.0344 & 0.0303 & 0.0498 & 0.0169 & -0.0780 \\
& $(0.3460)$ & $(1.6960)$ & $(0.9585)$ & $(1.2786)$ & $(0.4375)$ & $(-2.1409)$ \\
& 0.0040 & 0.0418 & 0.0437 & 0.0735 & 0.0365 & -0.0085 \\
& $(0.4052)$ & $(2.4552)$ & $(1.7558)$ & $(2.3486)$ & $(1.4678)$ & $(-0.2879)$ \\
High BM & & & & & & \\
& & & & & & \\
Medium BM & $(0.0039$ & 0.0227 & 0.0168 & 0.1512 & 0.1029 & -0.0101 \\
& -0.0137 & $(0.7520)$ & $(0.3084)$ & $(3.0499)$ & $(1.5889)$ & $(-0.1810)$ \\
Low BM & $(0.6644)$ & $(1.0057)$ & $(0.2602)$ & $(0.6865)$ & $(2.3596)$ & $(-1.4321)$ \\
& 0.0063 & 0.0228 & 0.0074 & 0.0235 & 0.0973 & -0.0581 \\
& $(-1.0743)$ & $(0.7909)$ & $(0.8178)$ & $(2.0263)$ & $(1.1558)$ & $(0.0458)$ \\
\hline \hline
\end{tabular}

Note: This table reports the long term abnormal stock returns following Moody's downgrade announcements, only for the stocks that did not have a subsequent downgrade in the three-year period following the initial downgrade. Average cumulative abnormal returns (CAR) are computed for different horizons. Firm specific CARs are the sums of the difference in the log monthly returns of the firm and a benchmark portfolio with similar size, book-to-market, and default risk (DLI) characteristics. Twenty-five benchmark portfolios are constructed from the intersection of two independent sorts of stocks into five size, and five BM portfolios. Subsequently, each of the twenty-five portfolios is subdivided into five portfolios according to the DLI of the stocks. This procedure gives rise to the construction of 125 benchmark portfolios. The CARs reported in the table are the average (mean) cumulative abnormal returns of the stocks that fall within the categories we examine. 
Table 10: Average Deviation from Benchmark Portfolios in the computation of Abnormal Returns

Panel A: Adjustment by only Size and BM

\begin{tabular}{lccc}
\hline \hline & Ave. Dev. (BM) & Ave. Dev. (Cap) & Ave Dev. (DLI) \\
ALL & 0.2207 & 0.1837 & 5.3896 \\
Grade A & 0.0402 & 0.7847 & -0.1680 \\
Grade B & 0.1857 & -0.0266 & 4.7784 \\
Grade C & 0.6982 & -0.0132 & 18.1000 \\
\hline \hline
\end{tabular}

Panel B: Adjustment for Size, BM and Default Risk (DLI)

\begin{tabular}{lccc}
\hline \hline & Ave. Dev. (BM) & Ave. Dev. (Cap) & Ave Dev. (DLI) \\
ALL & 0.1355 & 0.2342 & 1.9227 \\
Grade A & 0.0337 & 0.7458 & -0.1276 \\
Grade B & 0.1148 & 0.0543 & 1.7379 \\
Grade C & 0.4093 & 0.0698 & 6.4380 \\
\hline \hline
\end{tabular}

Note: This table reports the average deviation between the size, BM, and DLI characteristics of the firm and the benchmark portfolio used for the computation of its abnormal return. Panel A presents the deviations when the abnormal returns are calculated as in Table 6. Panel B presents the deviations when the abnormal returns are calculated as in Table 8. 


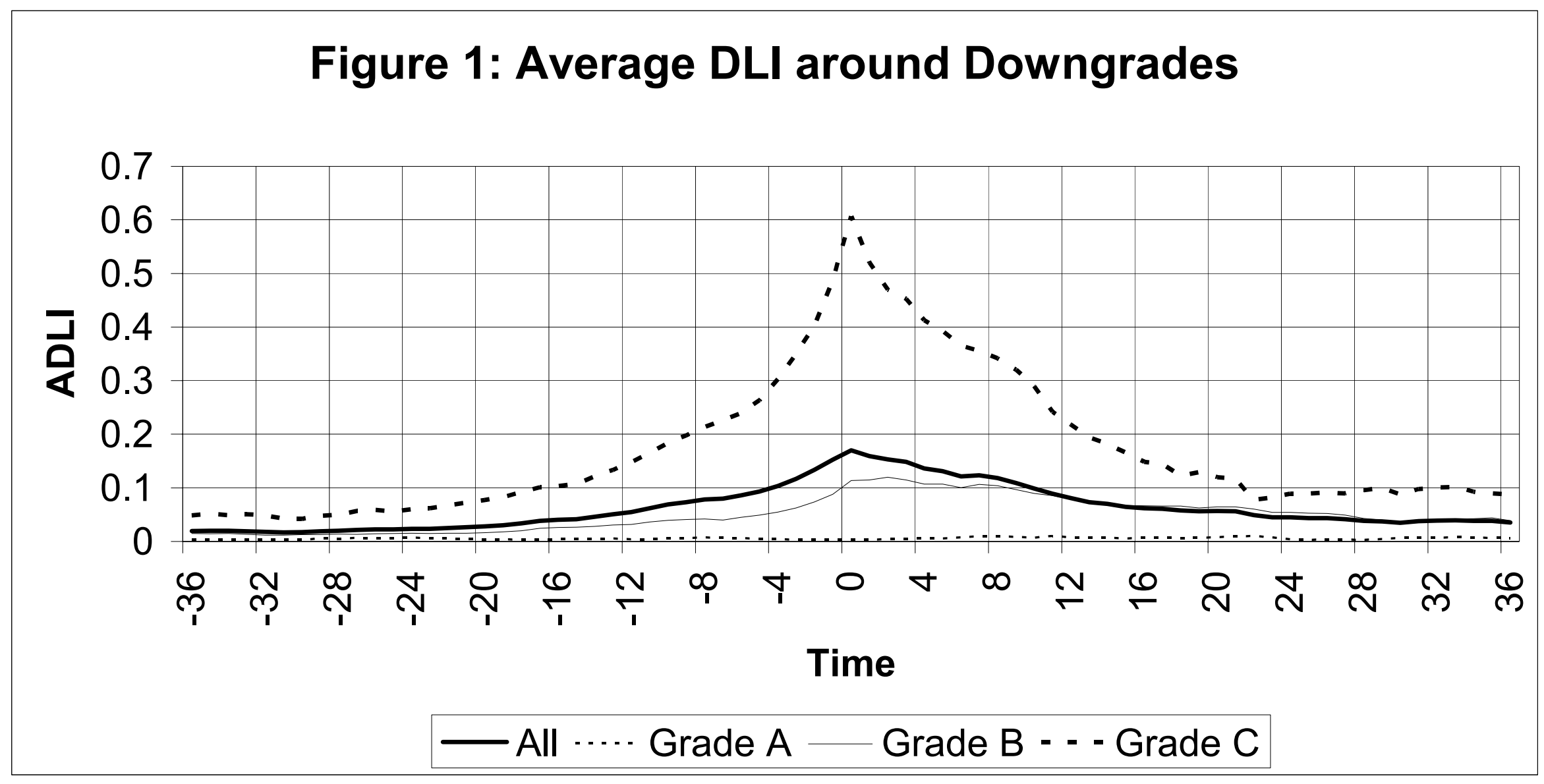

Note: This graph plots the average default likelihood indicator (ADLI) in a six-year window around Moody's announcement dates of downgrades. All announcements dates of downgrades in our database are lined up at time $=0$. Time is numbered in months away from the announcement. All refers to the ADLI of all stocks with downgrades. Grade A includes all the firms with corporate debt ratings of A, AA or AAA. Similarly, Grade B and Grade C include all stocks whose debt rating starts with B or C respectively. 


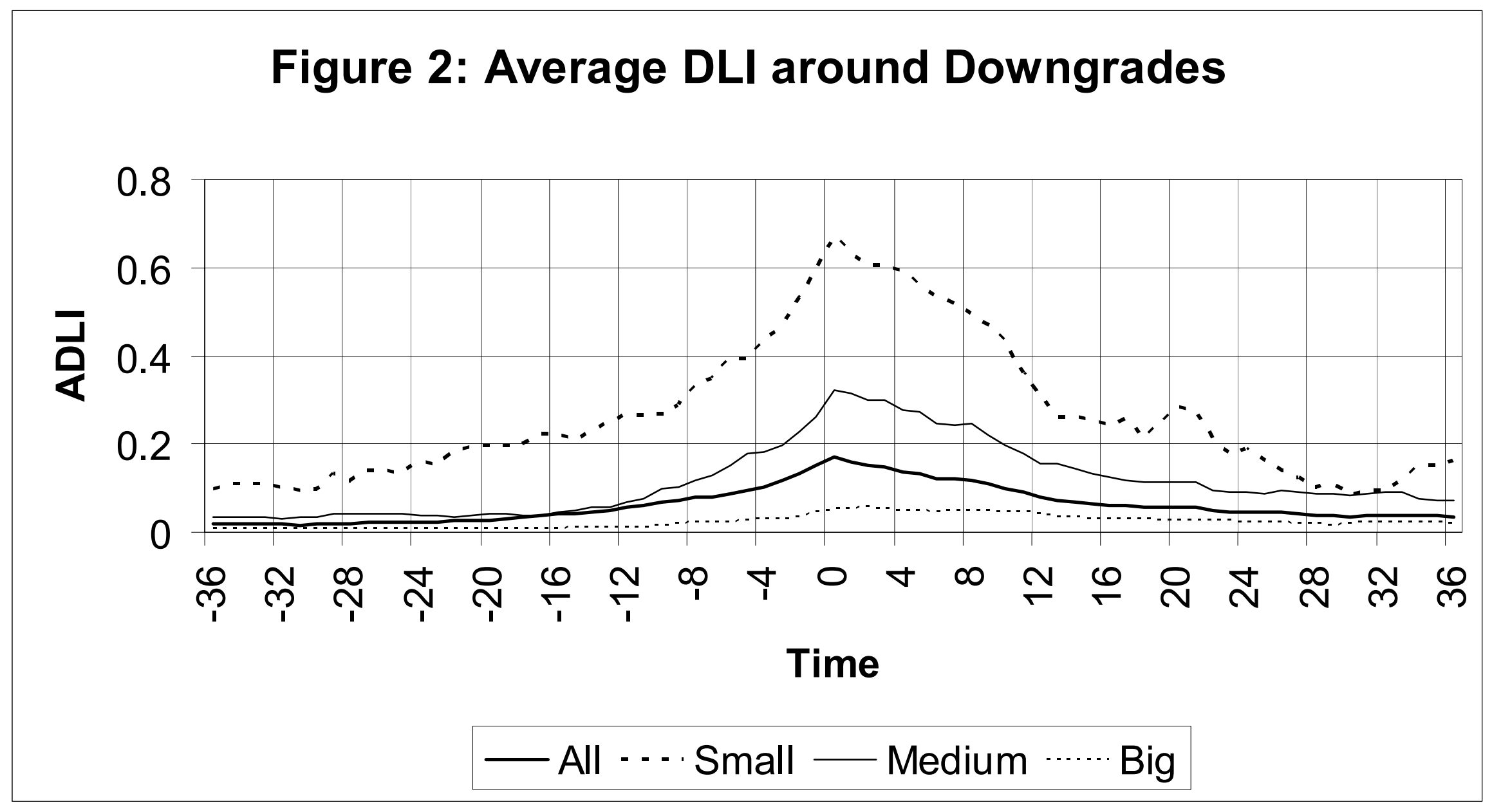

Note: This graph plots the average default likelihood indicator (ADLI) in a six-year window around Moody's announcement dates of downgrades. All announcements dates of downgrades in our database are lined up at time $=0$. Time is numbered in months away from the announcement. All refers to all stocks in our sample with downgrades. Small, Medium, and Big refer to the ADLI of stocks with downgrades and small, medium or big market capitalization, respectively. 


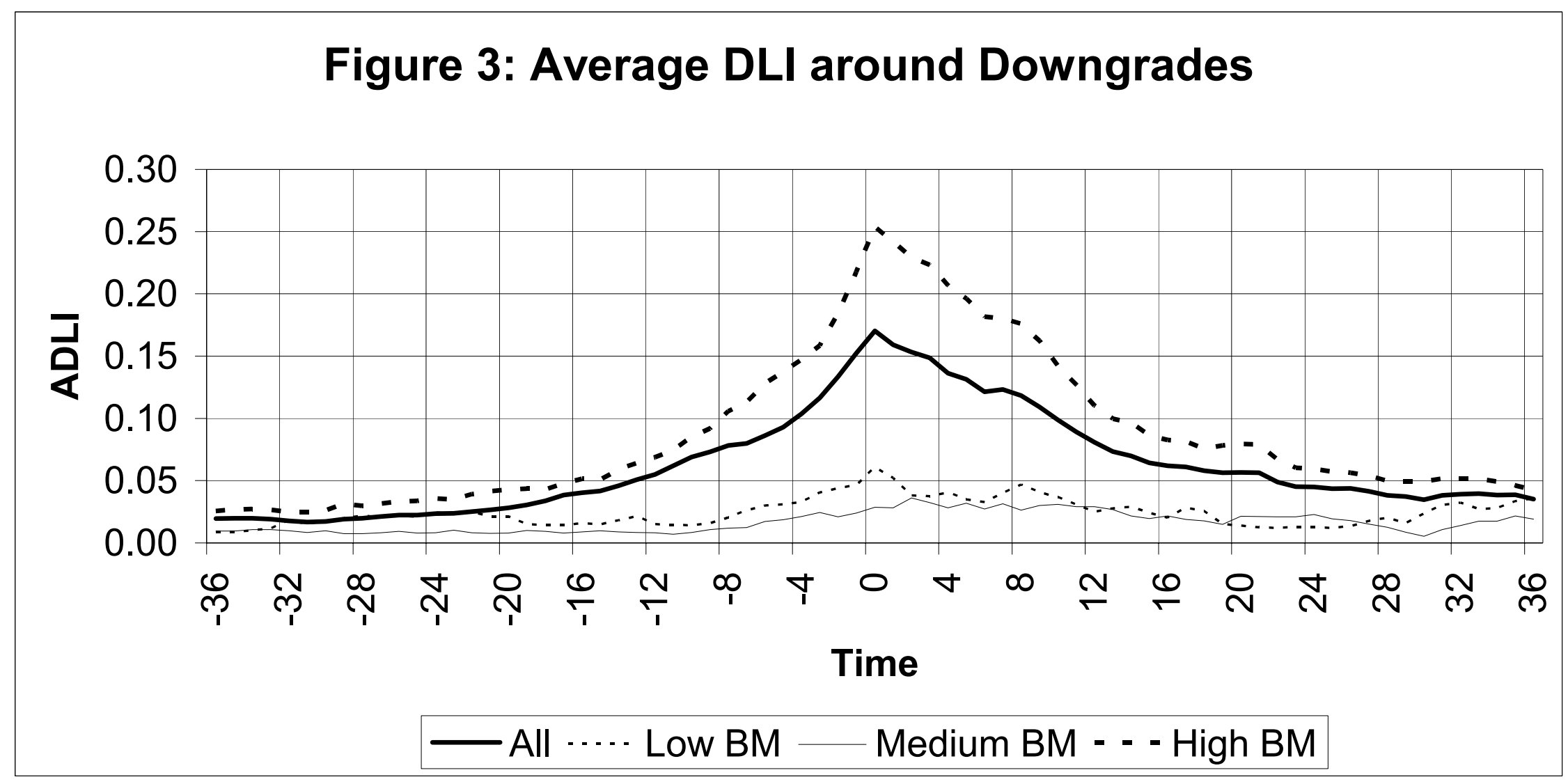

Note: This graph plots the average default likelihood indicator (ADLI) in a six-year window around Moody's announcement dates of downgrades. All announcements dates of downgrades in our database are lined up at time $=0$. Time is numbered in months away from the announcement. All refers to all stocks in our sample with downgrades. Low BM, Medium BM, and High BM refer to the ADLI of stocks with downgrades and low, medium or high book-to-market (BM), respectively. 


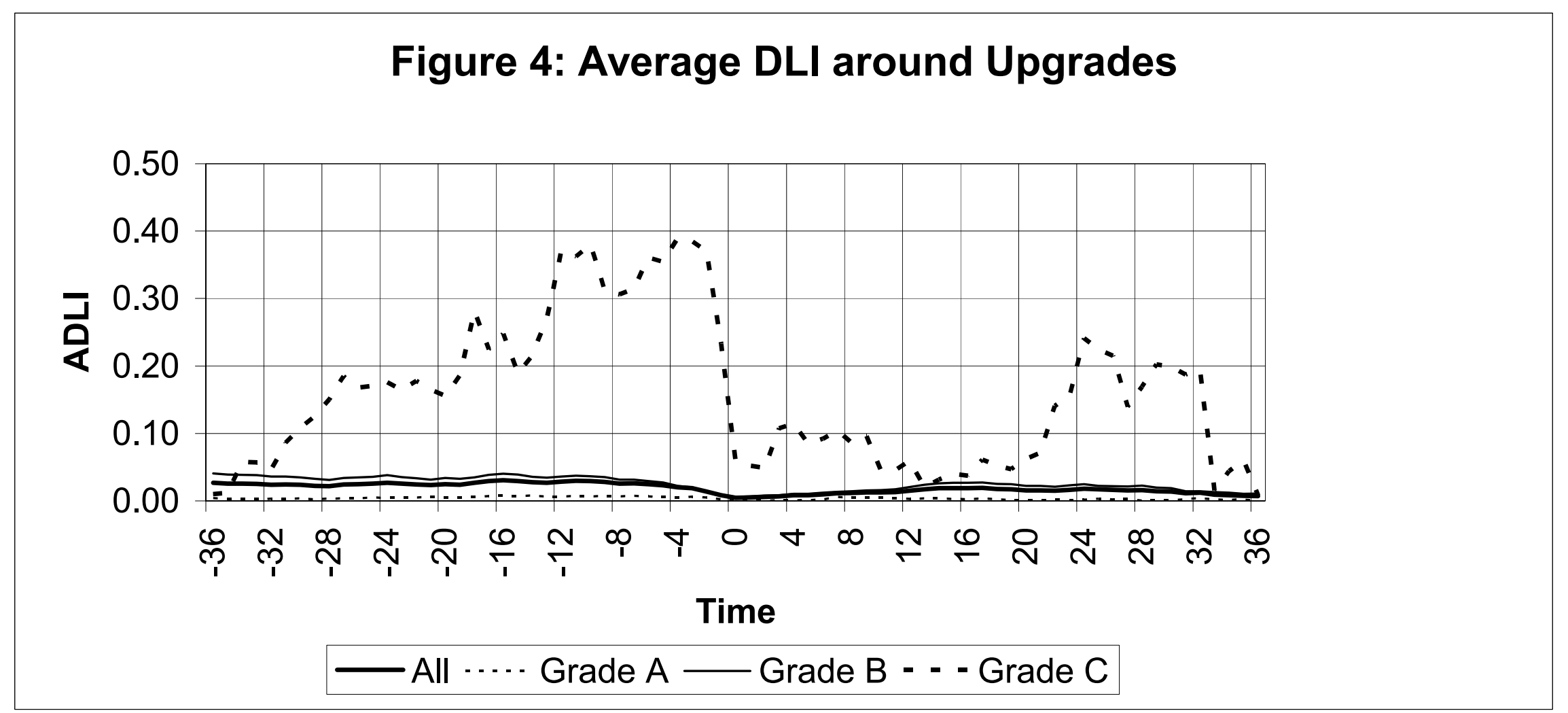

Note: This graph plots the average default likelihood indicator (ADLI) in a six-year window around Moody's announcement dates of upgrades. All announcements dates of upgrades in our database are lined up at time $=0$. Time is numbered in months away from the announcement. All refers to the ADLI of all stocks with upgrades. Grade A includes all the firms with corporate debt ratings of A, AA or AAA. Similarly, Grade B and Grade C include all stocks whose debt rating starts with B or C, respectively. 


\section{Figure 5: Annual Average Changes in Book Value of Debt Around Downgrades}

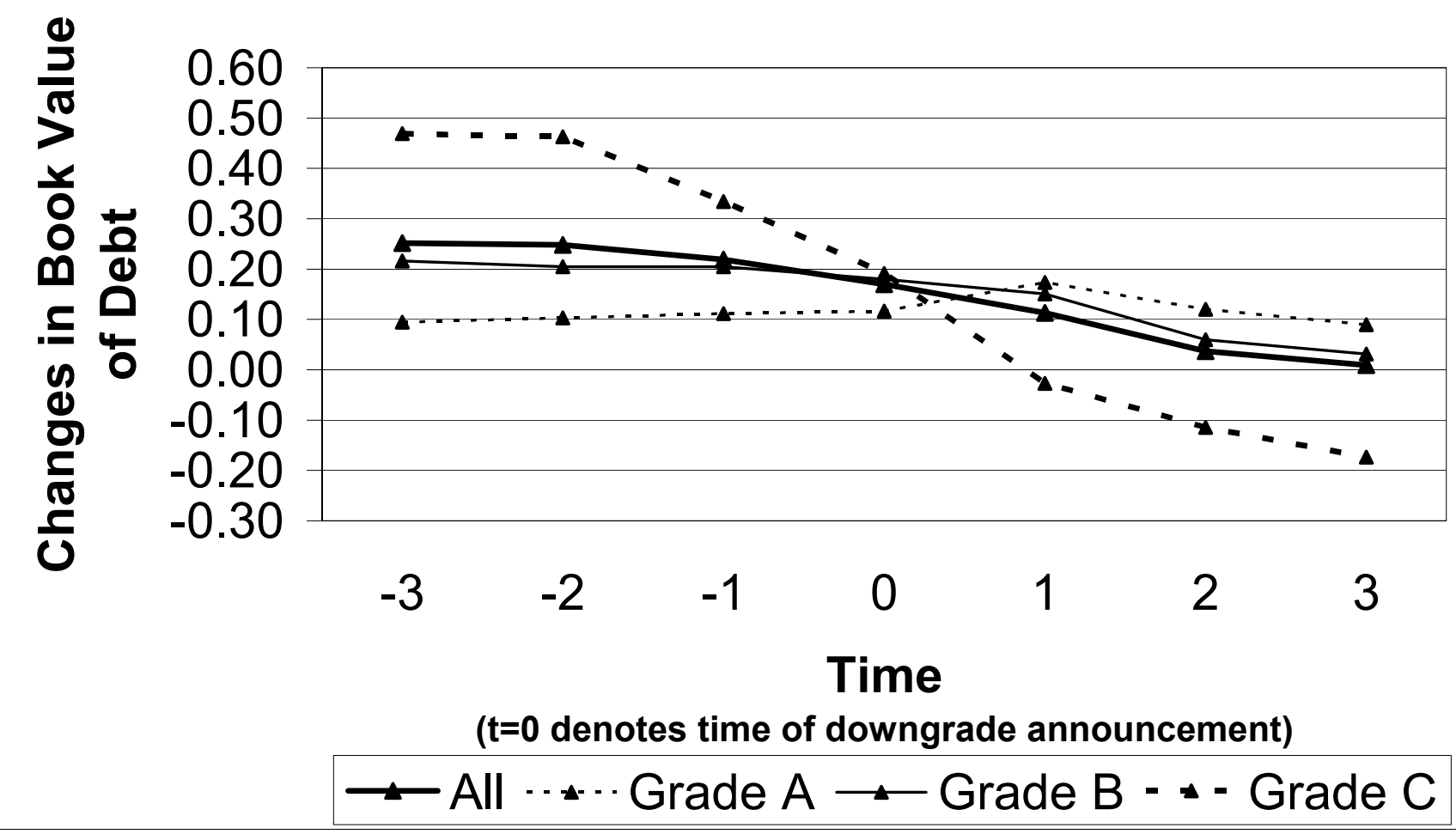




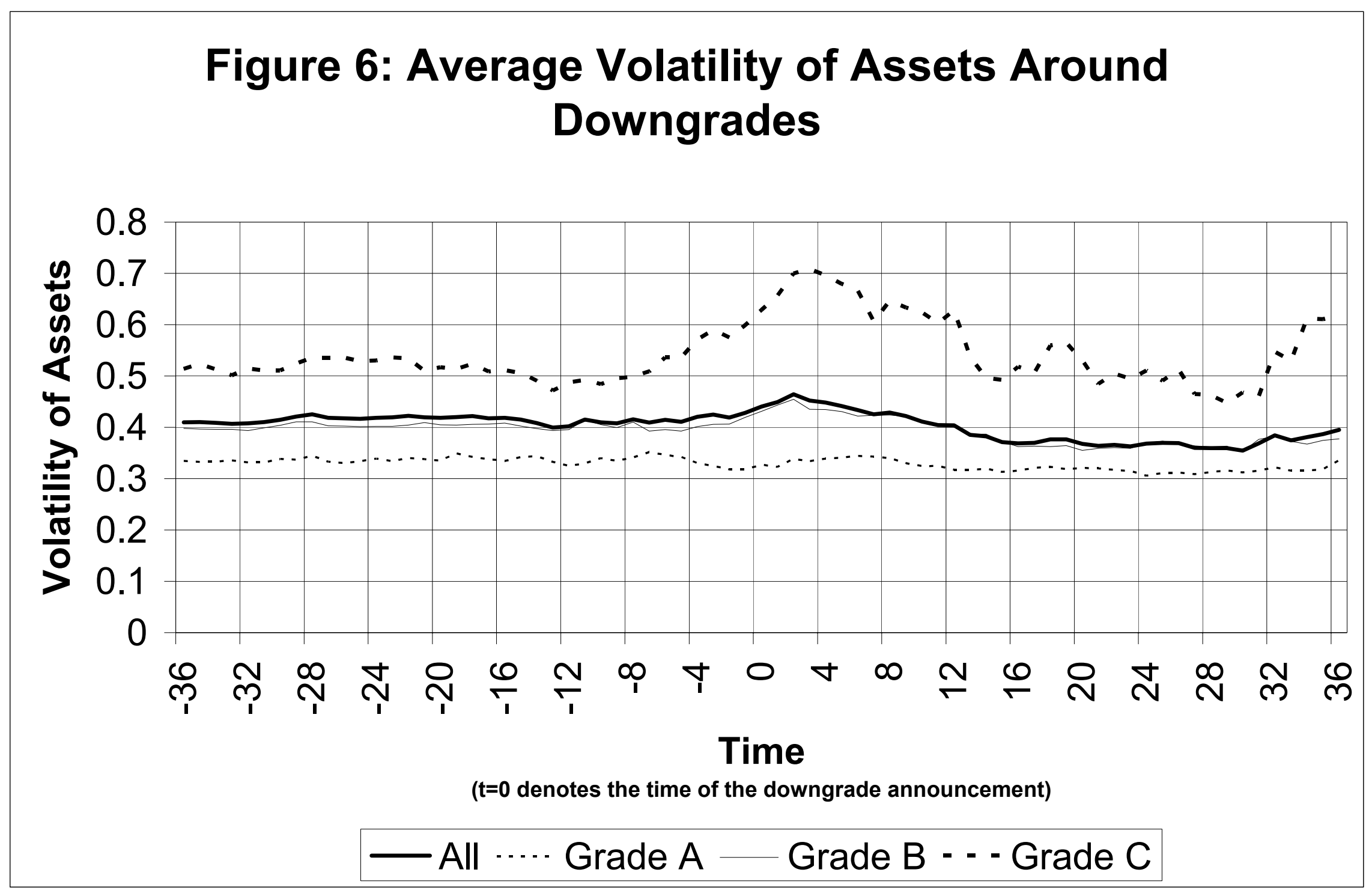




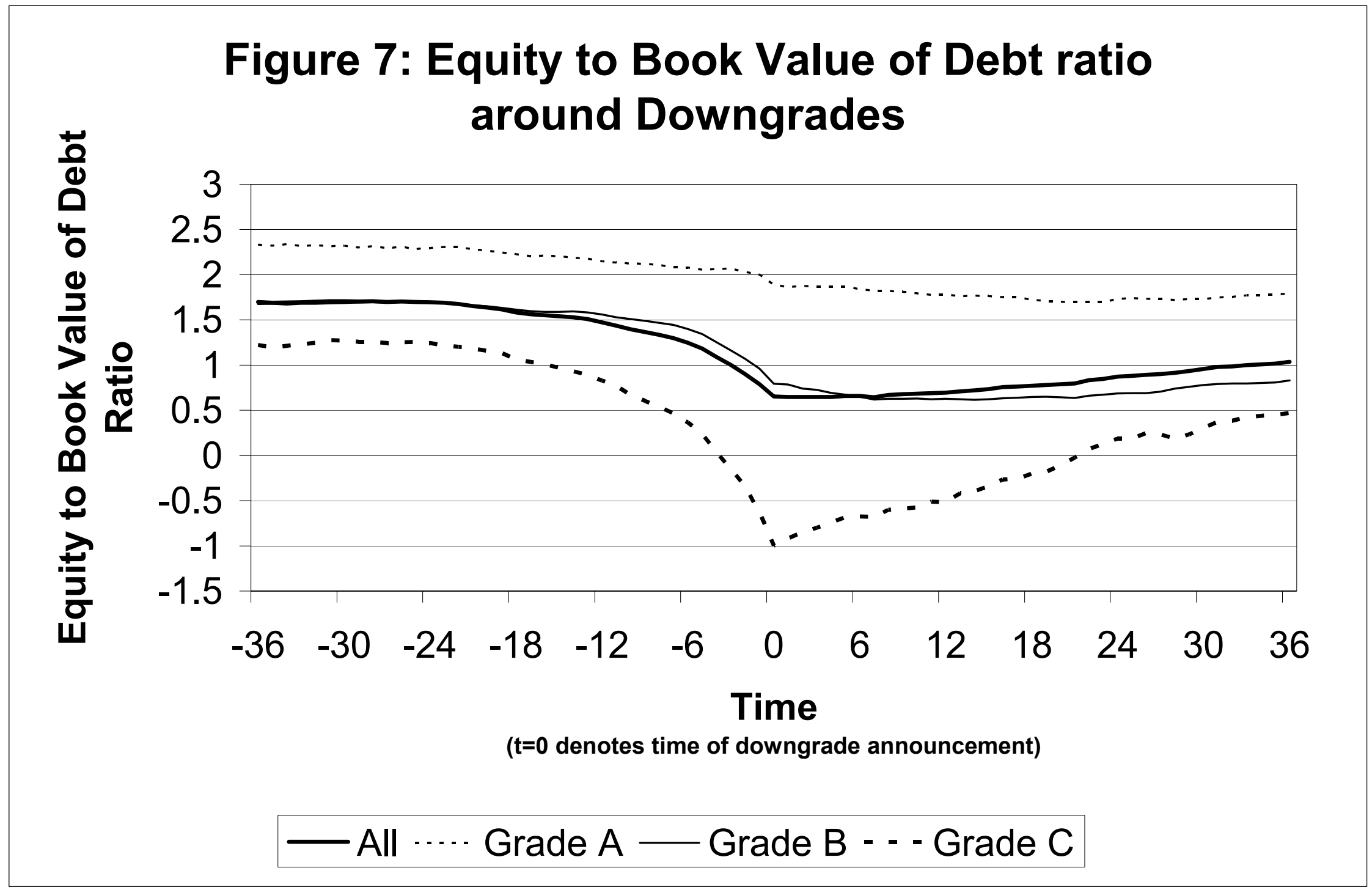




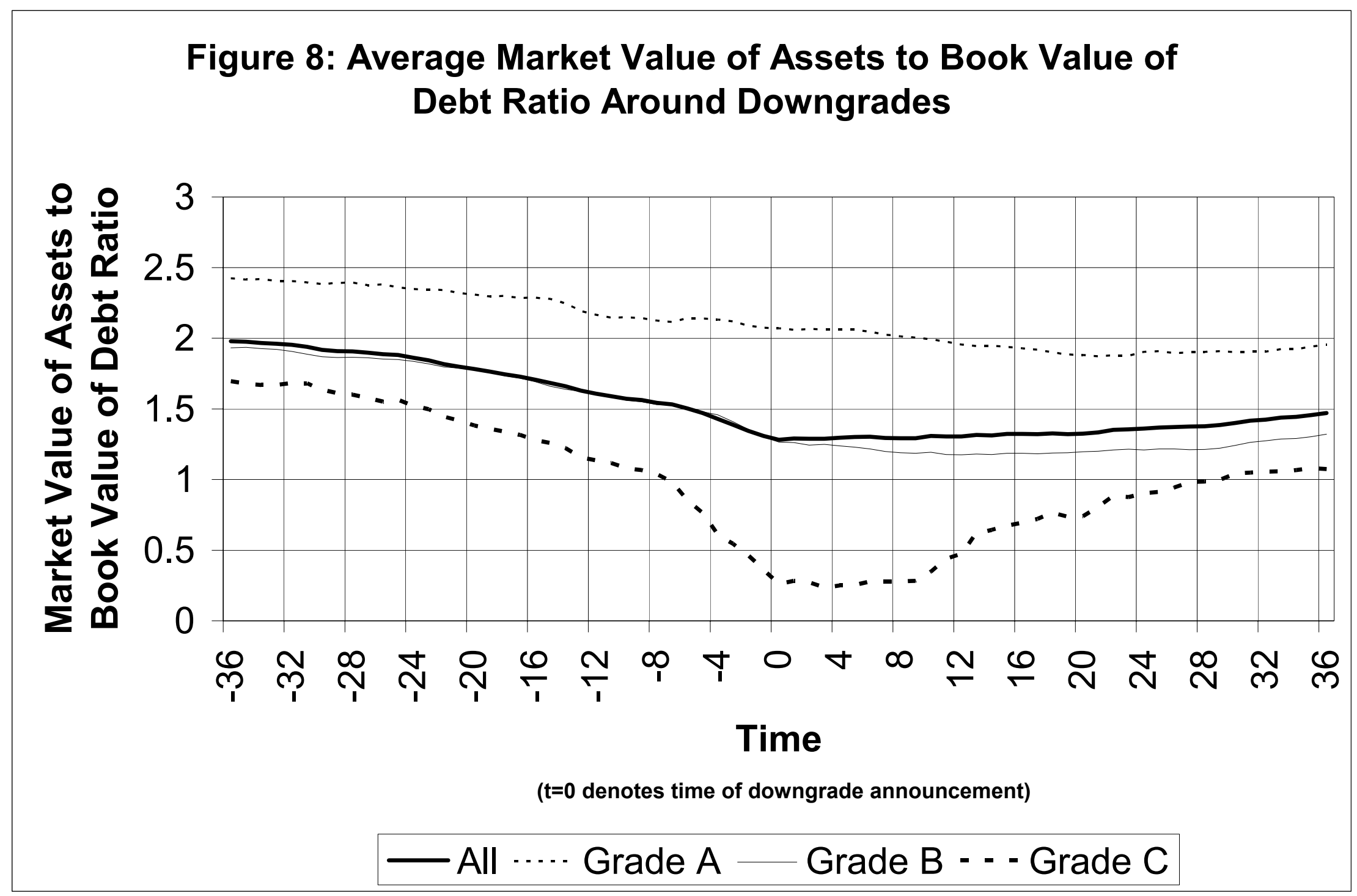

